Western University Scholarship@Western

Digitized Theses

Digitized Special Collections

1991

\title{
Entrepreneurs, Growth And Cycles
}

Louis Corriveau

Follow this and additional works at: https://ir.lib.uwo.ca/digitizedtheses

\section{Recommended Citation}

Corriveau, Louis, "Entrepreneurs, Growth And Cycles" (1991). Digitized Theses. 2030.

https://ir.lib.uwo.ca/digitizedtheses/2030

This Dissertation is brought to you for free and open access by the Digitized Special Collections at Scholarship@Western. It has been accepted for inclusion in Digitized Theses by an authorized administrator of Scholarship@Western. For more information, please contact tadam@uwo.ca,

wlswadmin@uwo.ca. 


\title{
ENTREPRENEURS, GROWTH AND CYCLES
}

\author{
by \\ Louis Corriveau
}

Department of Economics

Submitted in partial fulfilment

of the requirements for the degree of

Doctor of Philosophy

Faculty of Graduate Studies

The University of Westem Ontario

London, Ontario

August 1991

(c) Louis Corriveau 1991 
Onama ranada

Kia ond

The author has orented en irrevocable nonexclusive isence ellowing the Nealiond Lbrery of Cenada bo reproduce, ben, distrbute or sell copies of his/her thesis by any meens and in any form or format, making this thesis avelable to interested persons.

The author retains ownerstip of the copyright in his/her thesis. Neither the thiesis nor substantial extracts from it may be printed or otherwise reproduced without hisher permission.
L'auteur a accordé une licence irrérocable et non exchusive permettant à la Bibliotheque netionale du Cenada de reproduire. preter. cistribuer ou vendre des copies de sa these de quelque manière et sous quelque forme que ce soit pour mettre des exemplaires de cette thèse à la disposition des personnes intéressées.

L'auteur conserve la propriété du droit d'auteur qui protège sa thèse. Ni la thèse ni des extraits substantiels de celle-ci ne doivent etre imprimés ou autrement reproduits sans son autorisation. 


\begin{abstract}
We study how strategic considerations which pertain to the microeconomic process of innovation affect the macroeconomic process of growth and its efficiency. To a lesser extent, we also study how they may cause fluctuations to occur. We do this by the means of two models.
\end{abstract}

The first model pictures a one-good economy where long-run growth and output fluctuations are endogenous consequences of the decisions taken by entrepreneurs on the allocation of their resources between production and innovation in a Markovian sequence of one-period games. We show, first, that the log of output follows a process with random walk characteristics; second, that a recession is the consequence, not of a Kydland and Prescott [1982] negative shock on technology, but of the reallocation of factors in the face of an "increased opportunity" ex ante which the entrepreneurs fail to exploit ex post; third, and finally, that, although any generation could make itself unilaterally better off by reducing its level of research, the one-good economy is intertemporally efficient in that such a move would imply a reduction in the level of welfare of future generations.

The second model pictures an infinite-horizon multisector economy where endogenous growth in the aggregate results from the innovation races which go on in each and every sector. We study the coordination failures that may arise and uncover five externalities which have strategic implications. We show that, at least for some parametrisations of our model, there exist multiple stationary equilibria associated with 
different rates of growth. One noteworthy source of that multiplicity is the "real income effect", which relates the resources spent on research to the real value of nominal incomes through the lower real prices innovations eventually entail. Finally, we show that, because agents are infinitely-lived and many externalities occur, the multisector economy is intertemporally inefficient. Furthermore, we show that, depending upon the particular values taken by the parameters, the competitive process may lead to either overinvestment or underinvestment in research; i.e. the rate of growth may either be higher or lower than efficiency would warrant. 


\section{ACKNOWLEDGEMENTS}

I wish to thank the Chairman of my Thesis Committee, Professor Peter Howitt, as well as my other advisors, Professors David Laidler, Phil Reny and, initially, Peter Morgan, for their many helpful suggestions. All remaining errors are, of course, mine.

I also gratefully acknow!edge the support I received from the Social Sciences and Humanities Research Council of Canada under Doctoral Fellowships 452 - 85 - 0413, 453 - 86 - 0135, 453 - 87 - 1040 and 452 - 88 - 1746. 
TABLE OF CONTENTS

Page

CERTIFICATE OF EXAMINATION

ABSTRACT

ACKNOWLEDGEMENTS

TABLE OF CONTENTS

LIST OF FIGURES

CHAPTER 1 - GENERAL INTRODUCTION 1

CHAPTER 2 - ENTREPRENEURS, GROWTH AND CYCLES 7

2.1 Introduction 7

2.2 The Model 10

2.3 The Equilibrium of the Representative Entrepreneur 14

2.4 The Equilibrium of the Large Competitive Economy 20

2.5 Long-run Growth and the Cycle 26

2.6 Conclusion 32

Footnotes $\quad 34$

CHAPTER 3 - ON THE MULTIPLICITY OF ENDOGENOUS GROWTH RATES

3.1 Introduction $\quad 35$

3.2 The Model 38

3.3 The Representative Entrepreneur's Problem 48

3.4 The Multiplicity of Stationary Equilibria

3.5 Robustness 62

3.6 Conclusion 63

Footnotes 65

CHAPTER 4 - ENDOGENOUS GROWTH AND WELFARE 66

4.1 Introduction 66

4.2 The One-Good Economy 68

4.3 The Multisector Economy

Footnotes $\quad 87$

$\begin{array}{ll}\text { BIBLIOGRAPHY } & 90\end{array}$

VITA 98 


\section{LIST OF FIGURES}

Figure

1

2
Description

Multiplicity of stationary equilibria

Robustness of the multiplicity
Page

88

89 
The author of this thesis has granted The University of Western Ontario a non-exclusive license to reproduce and distribute copies of this thesis to users of Western Libraries. Copyright remains with the author.

Electronic theses and dissertations available in The University of Western Ontario's institutional repository (Scholarship@Western) are solely for the purpose of private study and research. They may not be copied or reproduced, except as permitted by copyright laws, without written authority of the copyright owner. Any commercial use or publication is strictly prohibited.

The original copyright license attesting to these terms and signed by the author of this thesis may be found in the original print version of the thesis, held by Western Libraries.

The thesis approval page signed by the examining committee may also be found in the original print version of the thesis held in Western Libraries.

Please contact Western Libraries for further information:

E-mail: libadmin@uwo.ca

Telephone: (519) 661-2111 Ext. 84796

Web site: http://www.lib.uwo.ca/ 


\section{GENERAL INTRODUCTION}

That tastes, techniques of production and endowments are the primitives of an economic system is a core principle of economic analysis. This principle, which can be traced back to John Stuart Mill's Principles of Political Economy [1871], is the central message of Debreu's [1959] Theory of Value and most of contemporary economics consists in the reduction of various phenomena to that fundamental structure of explanation. Indeed, a major success of the Walrasian Research Programme was provided by the Kydland and Prescott's [1982] Real Business Cycle theory whose contribution was to explain in Walrasian language the persistence and recurrence of macroeconomic fluctuations, a phenomenon which, until then, had remained outside its scope.

While tastes, techniques of production and endowments may, in many cases, safely be taken as given, economists have for long known them to be variable and recognized the importance of their variability in the explanation of economic dynamics. Indeed, Schumpeter proposed, as early as [1911] and as an extension of the Walrasian construction, a vision of the process of economic development where the role of technological innovation was crucial. The Schumpeterian vision was never forgotten and it influenced, in due course, the now standard models of "patent races" in the Industrial Organization literature. Those models are reviewed in Reinganum [1984], Reinganum [1989] and Tirole [1988; chap. 10].

Despite the recognition of technological progress as an important source of economic growth, for a while growth theorists focused on the role of capital accumulation and assumed the process of technological change to be exogenous. Notable exceptions 
innovations.

Third, while Romer [1986] and [1990] assume a deterministic process of knowledge acquisition, we follow again the industrial organization literature and take it for granted that a potential innovator can never really know in advance if he will succeed. What we postulate, instead, is that the more resources he spends the more likely he is to innovate. A similar assumption was made in the related work of Aghion and Howitt [1989] and followed in Grossman and Helpman [1991].

Fourth, we depart from the standard patent race models, such as Loury [1979], Lee and Wilde [1980] or Dasgupta and Stiglitz [1980], in that, whereas they concern themselves with the partial equilibrium of an industry where the winner of a once-and-for-all innovation race makes a capital gain whose value is exogenous, we study the general equilibrium of an economy where the race for innovations never stops and where the value of an innovation is endogenous.

Fifth, we also depart from the patent race literature in that we assume discoveries to be stochastically independent events and allow an arbitrary and endogenous number of them to occur in the same period : potentially none, one or many.

Sixth, we construct a framework where market structures are endogenous.

Seventh, unlike Romer [1986] and [1990] and Lucas [1988], the models we build are compatible with the creation of rents that provides the search for innovations with its economic rationale and with the destruction of existing rents that follows as a consequence. 
Eighth, as the one-good model emphasizes, the possibility that simultaneous discoveries may occur in the same sector gives the innovation race a rent-seeking aspect, whose strategic implications affect the rate of growth and its efficiency.

Ninth, as the multisector model shows, the possibility that simultaneous discoveries may occur in different sectors induces various spillovers across sectors and over time, including those associated with real prices that fall over time. Those spillovers have an impact on the innovators' rents and their strategic implications affect the rate of growth and its efficiency.

Tenth, and finally, the link which exists between the innovation race and the macroeconomic fluctuations in the one-good cconomy yields a necessary and sufficient condition for a recession to occur. This provides an alternative to the Kydland and Prescott's [1982] interpretation of the downturns in output.

This monograph is divided in four chapters. The first is the current introduction. In the second, we expound a Schumpeterian model of a one-good economy where long-run growth and output fluctuations are endogenous consequences of the decisions taken by entrepreneurs on the allocation of their resources between production and innovation in a Markovian sequence of one-period games. We show, first, that the log of output follows a process with random walk characteristics, i.e. that ours is indeed a model of growth and fluctuations. Second, we show that the technological change process is variable and that its variability causes the rate of productivity growth to fluctuate, as Prescott [1986] arg!:as in his Defence of the Real Business Cycle research programme. However, we prove that those fluctuations do not, by themselves, imply the occurrence of any recession, a result which both provides a counter-example to Prescott's claim that they constitute a sufficient explanation of the downturns, and may also explain why he finds 
that the Real Business Cycle models have good, but not perfect, fit. Third, and finally, we give a necessary and sufficient condition for a recession to occur which shows that a downturn in output is the consequence, not of a Kydland and Prescott [1982] negative shock on technology, but of the reallocation of factors in the face of an "increased opportunity" ex ante which the entrepreneurs fail to exploit ex post.

In the third chapter, we expound a model of an infinite-horizon multisector economy where growth is endogenous and results from the actions of entrepreneurs who seek, find and exploit the profit opportunities which arise out of process innovations. The model is specified in such a way that it turns out to be tractable in spite of its large size. Furthermore, we can describe, in probabilistic terms, the industrial organization of the whole economy and determine the probability distribution of prices.Though what happens in any given sector is random, we can show the economy to be deterministic in the aggregate. The representative entrepreneur's problem can thus be written and solved. We study the coordination failures that may arise and uncover five externalities which have strategic implications : the "lagged real income effect", the "contemporaneous real income effect", the "Shleifer effect", the "competition effect" and the "aggregate demand effect".

The lagged and contemporaneous real income eff $z$ cts relate the resources spent on research to the real value of nominal incomes and, in particular, to the real value of nominal rents. They occur because the benefits arising from the innovations are eventually transmitted to the consumers through lower real prices. The Shleifer effect relates the resources spent on research to the proportion of monopolistic sectors and, thereby, to the magnitude of the rents. Indeed, the second part of the relationship formed the original Shleifer [1986] effect. The competition effect relates the resources spent by the competitors of a potential innovator to the probability he will obtain a rent. The aggregate demand effect, finally, relates the resources spent on research in the economy as a whole 
to the demand for consumption goods and, thereby, to the value of the rents.

In the language of Bulow et al. [1985], the "lagged real income effect" generates positive spillovers and strategic complementarities, the "competition effect" and the "aggregate demand effect" generate negative spillovers and strategic substitutes, and, finally, the "contemporaneous real income effect" and the "Shleifer effect" generate spillovers of ambiguous signs and have ambiguous strategic implications. Thanks to the presence of those externalities, we can show that, at least for some parametrisations of our model, there exist multiple stationary equilibria associated with different rates of growth. We also interpret our results and relate them to the previous literature.

In the fourth chapter, finally, we carry out the welfare analysis of the models introduced in the two preceding chapters. We consider, first, the model of Chapter 2 and show that, in any generation, the possibility of simultaneous discoveries gives the innovation race a rent-seeking aspect. However, because the benefits accruing to future gencrations are not appropriable, the research effort of one generation is a free gift to subsequent generations. It follows that, while any generation could make itself unilaterally better off by reducing its level of research, the one-good economy is intertemporally efficient in that such a move would imply a reduction in the level of welfare of future generations. Next, we consider the model of Chapter 3 and show that, because agents are infinitely-lived and many externalities occur, the multisector economy is intertemporally inefficient. Furthermore, we show that, depending upon the particular values taken by the parameters, the competitive process may lead to either overinvestment or underinvestment in research; i.e. the rate of growth may either be higher or lower than efficiency would warrant. 


\section{ENTREPRENEURS, GROWTH AND CYCLES}

\subsection{Introduction}

The contribution of Kydland and Prescott [1982] was to show how a series of exogenous technological shocks could generate, through the intertemporal smoothing behaviour of a representative agent, some typical features of the business cycle. While their work was a major success for the Walrasian Research Programme in that it provided an explanation of the macroeconomic fluctuations in the language of that theory, it gave rise to two types of criticisms : first, on theoretical grounds, that the shocks may themselves be in need of an economic explanation; and second, on empirical grounds, that it is hard to think of many instances of the adverse technological shocks which are needed to explain the downturns in output.

Kydland and Prescott's model was developed from the neoclassical model of capital accumulation in which the growth process is exogenous. An endogenisation of technological change was done in Romer [1986], a framework to which King and Rebelo [1988] added exogenous shocks to obtain a real business cycle model with endogenous growth. Romer's idea was that technological change was driven by the advance of knowledge, that knowledge was a capital capable of being accumulated, and that its process involved, at the individual level, an external economy of scale which produced increasing returns at the aggregate level. He developed and illustrated his vision in [1990], where he assumed knowledge to be embedded in physical capital and an advance in knowledge to take the form of an increasing list of products. 
The growth theory of Romer can be criticized on two related grounds. First, it assumes a deterministic process of knowledge acquisition. Because an agent can never really know in advance what he will discover, nor if he will discover anything at all, it seems more natural to conceive of learning as an essentially uncertain process. Second, it assumes a framework which cannot account for the process of Schumpeterian competition, with its creation and destruction of rents, that provides the search for innovations with its economic rationale.

Our work attempts to develop Schumpeter's [1911] vision and provide a theory of economic dynamics which is simpler than the New Classical one, in that both long-run growth and output fluctuations become consequences which follow from the same cause, the actions of entrepreneurs who seek, find and exploit the profit opportunities which arise out of process innovations. In the present chapter, our aim is to construct a prototype model of our alternative conception. We make no claim as to the realism of the hypotheses we will investigate; our purpose, which is purely theoretical, is to build the simplest possible model which can illustrate our theory and show its consistency.(1)

We consider a Markovian world made up of a sequence of one-period one-good economics. The free transmission of knowledge is the only link between periods. In each of them, a two-stage game takes place. It involves both an innovation race, which determines the probabilistic distribution of knowledge among agents, and the allocation and pricing of the remaining resources as factors of production. In assuming a stochastic innovation process, our model follows the literature on patent races which is reviewed in Reinganum [1984], Reinganum [1989] and Tirole [1988]. It differs, however, from the standard models therein, such as Loury [1979] or Dasgupta and Stiglitz [1980], in that we assume innovations to be stochastically independent events and thus allow an arbitrary and endogenous number of them to occur in the same period: 
potentially none, one or many. Furthennore, and much more fundamentally, whereas they concern themselves with the partial equilibrium of an industry where the winner of a once-and-for-all innovation race makes a capital gain whose value is exogenous, we study the general equilibrium of an economy where the race for innovations never stops, where the value of an innovation is endogenous and where the distribution of the gains is also endogenous.

Our model has three main positive implications. First, the log of output follows a process with random walk characteristics, a result which makes our approach at least crudely compatible with the empirical evidence of Nelson and Plosser [1982] and Campbell and Mankiw [1987]. Second, the technological change process is variable and its variability causes the rate of productivity growth to fluctuate, as Prescott [1986] argues in his Defence of the Real Business Cycle research programme. However, those fluctuations do not, by themselves, imply the occurrence of any recession, a result which both provides a counter-example to Prescott's claim that they constitute a sufficient explanation of the downturns, and may also explain why he finds that the Real Business Cycle models have good, but not perfect, fit. Third, and finally, a downturn in output is caused, not by a negative shock on technology as in Kydland and Prescott [1982], but by the increased allocation of factors to innovation in the face of an increased opportunity ex ante the consequent reduction in the allocation of factors to production, and the failure of the entrepreneurs to innovate which leaves the technology of production as it was. Note that we mean by an increased opportunity a state where, prior to the innovation race and conditional on any given factor allocation, the expected rate of productivity growth is higher. 


\subsection{The: "odel}

Consider a sequence of economies populated by an arbitrary, but fixed, number $\mathrm{n}$ of identical agents who live for one period only. In each single period economy, a two-stage game takes place. In the first stage, each individual is endowed with a quantity $h$ of resources. He ${ }^{(2)}$ may supply a quantity I as factors of production and use a quantity s to seek an innovation. His resource constraint is therefore

$h=1+s$

Each player's objective is to maximize his expected end-of-period consumption $c$ of the one available good.

Were an entrepreneur to make an innovation, he would be able to improve upon the must efficient technique of production known in the preceding period, which is now common knowledge and embodied a production parameter $\mu_{\mathrm{a}}$. He would have access to a production parameter $\mu_{\mathrm{s}}\left(\mu_{\mathrm{s}}>\mu_{\mathrm{a}}\right)$, the production function being linear. To put it in another way, each individual faces the opportunity of a relative improvement in technology $q$, where $\mu_{\mathrm{s}}=(1+q) \mu_{\mathrm{a}} \cdot(3)$

The lei.. ing process is uncertain, however, and the probability of a discovery by a given individual is a function p of the resources allocated to opportunity seeking by that individual. We assume that individual discoveries are independent events and that the function $p$ is of class $C^{2}$ and satisfies $p(0)=0, p(s) \geq 0, p(s)<1, p^{\prime}(s)>0$ and $p^{n}(s)<0$. We also assume that the individuals are identical with respect to their learning abilities, so that both the relative opportunity and the probability function of its occurrence are the 
same for each and every one of them.

Once the distribution of knowledge and, as a result, the structure of the market is determined, the second stage of the game occurs. It involves the allocation of factors of production and the determination of factor prices through a simple Bertrand game.

Since the overall game we have defined is symmetric, we can solve it for a Symmetric Nash Equilibrium, the symmetry assumption being the game theoretic version of the pervasive representative agent assumption. Solving the game backwards, three cases are possible whose respective probabilities depend on the vector $s=\left(s^{1}, \ldots, s^{n}\right)$ of resources allocated to opportunity seeking by the various individuals in the first stage. In the first case, individual i can make a discovery and obtain a monopoly over the new technological knowledge. He can exploit it, besides increasing the productivity of his own factors of production, by hiring the other people's and paying them what they would have received had they worked with the old technolcgy. This class of events provides him with consumption

$c^{i}=\mu_{3}\left(h-s^{i}\right)+\left(\mu_{s}-\mu_{2}\right)(n-1)\left(h-s^{-i}\right)$

and occurs with probability $p\left(s^{i}\right)\left(1-p\left(s^{-i}\right)\right)^{n-1}$, where $s^{-i}$ designates the allocation made by agents other than $i$.

In the second case, multiple discoveries may occur, either because the individual makes a discovery without obtaining a monopoly or because, while he does not make a discovery, at least two of his competitors do. In both cases, Bertrand competition for the factors of production produces a remuneration of $\mu_{3}$, which the individual then enjoys on his remaining resources. This class of events provides individual $i$ with 
consumption

$\mathrm{c}^{\mathrm{i}}=\mu_{\mathrm{s}}\left(\mathrm{h}-\mathrm{s}^{\mathrm{i}}\right)$

and occurs with probability

$p\left(s^{i}\right)\left(1-\left(1-p\left(s^{-i}\right)\right)^{n \cdot 1}\right)$

$+\left(1-p\left(s^{i}\right)\right)\left(1-\left(1-p\left(s^{-i}\right)\right)^{n-1}-(n-1) p\left(s^{i}\right)\left(1-p\left(s^{-i}\right)\right)^{n-2}\right)$.

Finally, one can make no discovery with either nobody else making one or somebody else obtaining a monopoly. In each case, the individual receives a remuneration of $\mu_{\mathrm{a}}$ on his productive resources. This class of events provides individual $\mathrm{i}$ with consumption

$\mathbf{c}^{i}=\mu_{\mathbf{a}}\left(\mathbf{h}-\mathbf{s}^{i}\right)$

and occurs with probability $\left.\left(1-p\left(s^{i}\right)\right)^{n-1}-(n-1) p\left(s^{-i}\right)\left(1-p\left(s^{-i}\right)\right)^{n-2}\right)$

From what precedes, the Representative Entrepreneur's Problem can be written

as

MAX Ed

$0 \leq s^{i} \leq h$

where 


$$
\begin{aligned}
E c^{i}= & \left(\mu_{s}-\mu_{2}\right)(n-1)\left(h-s^{-i}\right) p\left(s^{i}\right)\left(1-p\left(s^{-i}\right)\right)^{n-1} \\
& +\left(\mu_{k}-\mu_{2}\right)\left(h-s^{i}\right)\left(p\left(s^{i}\right)+\left(1-p\left(s^{i}\right)\right)\right. \\
& \left.\quad\left(1-\left(1-p\left(s^{-i}\right)\right)^{n-1}-(n-1) p\left(s^{-i}\right)\left(1-p\left(s^{-i}\right)\right)^{n-2}\right)\right) \\
& +\mu_{a}\left(h-s^{i}\right)
\end{aligned}
$$

a formulation which allows an interpretation cast in opportunity cost terms.

Indeed, given that the entrepreneur devotes resources si to the exploration of potential opportunities, the first term of his objective function represents the monopoly rent which he expects to capture from his competitors if he is alone to have access to the new technological knowledge. The second term represents the expected technological rent which arises from the increased productivity of the entrepreneur's own resources when he has made a discovery, or when at least two of his competitors have made one and the competitive process has provided him with the result of their efforts. The third term, then, represents the output he will produce with certainty.

Multiplying throughout by $1 / h_{n}$, one finally obtains the equivalent objective

$$
\begin{aligned}
\pi\left(s^{i} ; s^{-i}\right)=\text { def } & q(n \cdot 1)\left(h \cdot s^{-i}\right) p\left(s^{i}\right)\left(1 \cdot p\left(s^{-i}\right)\right)^{n-1} \\
+ & q\left(h-s^{i}\right)\left(p\left(s^{i}\right)+\left(1-p\left(s^{i}\right)\right)\right. \\
& \left.\left(1 \cdot\left(1 \cdot p\left(s^{-i}\right)\right)^{n-1} \cdot(n \cdot 1) p\left(s^{-i}\right)\left(1 \cdot p\left(s^{-i}\right)\right)^{n-2}\right)\right) \\
+ & \left(h \cdot s^{i}\right)
\end{aligned}
$$

which shows the entrepreneur's decision does not depend on the absolute magnitudes $\mu_{8}$ and $\mu_{2}$, but only on the relative magnitude $q$. 


\subsection{The Equilibrium of the Representative Entrepreneur}

The assumption of a representative entrepreneur is analytically convenient in that it allows a simple derivation of the aggregate outcomes from the individual actions. Indeed, in our context, a market equilibrium s* will solve the following problem

$s=A R G M A X \pi(s, s)$

$$
0 \leq s^{i} \leq h
$$

The problem is so defined that our proof of the existence and uniqueness of the equilibrium has a direct economic interpretation.

\section{Proposition I}

The entrepreneurial game has exactly one Symmetric Nash Equilibrium $\mathbf{s}^{*}$. If $p^{\prime}(0) \leq 1 / n q h$, then $s^{*}=0$. If $p^{\prime}(0)>1 / n q h$, then the solution is interior.

Proof

\section{(Part 1)}

The objective is a continuous furiction. 


$$
\begin{aligned}
\text { Since } \pi_{i}= & q(n-1)\left(h-s^{-i}\right) p^{\prime}\left(s^{i}\right)\left(1-p\left(s^{-i}\right)\right)^{n-1} \\
& +q\left(h-s^{i}\right) p^{\prime}\left(s^{i}\right)\left(\left(1-p\left(s^{-i}\right)\right)^{n-1}\right. \\
& \left.\quad+(n-1) p\left(s^{-i}\right)\left(1-p\left(s^{-i}\right)\right)^{n-2}\right) \\
& -q\left(1-\left(1-p\left(s^{i}\right)\right)\left(1-p\left(s^{-i}\right)\right)^{n-1}\right. \\
& \left.\quad-(n-1)\left(1-p\left(s^{i}\right)\right) p\left(s^{-i}\right)\left(1-p\left(s^{-i}\right)\right)^{n-2}\right) \\
& -1
\end{aligned}
$$

we have

$$
\begin{aligned}
\pi_{s i} i= & q(n-1)\left(h-s^{-i}\right) p^{n}\left(s^{i}\right)\left(1-p\left(s^{-i}\right)\right)^{n-1} \\
& -\left\{2 q p^{\prime}\left(s^{i}\right)-q\left(h-s^{i}\right) p^{\prime \prime}\left(s^{i}\right)\right\} \\
& \cdot\left(\left(1-p\left(s^{-i}\right)\right)^{n-1}+(n-1) p\left(s^{-i}\right)\left(1-p\left(s^{-i}\right)\right)^{n-2}\right) \\
< & 0
\end{aligned}
$$

and the objective is also strictly concave.

Hence, the reaction correspondence $r:[0, h] \rightarrow[0, h]$ exists and is a function, where $r\left(s^{-i}\right)=$ def ARG MAX $\pi\left(s^{i}, s^{-i}\right)$.

$$
0 \leq s^{i} \leq h
$$

The function is continuous by the Maximum Theorem ( see, for instance Debreu [1959, Prop. 1.8.4] ) and Equation 2.4 has, therefore, at least one solution. 


\section{( Part 2)}

If $p^{\prime}(0) \leq 1 / n q h$, then

$\left.\pi_{8} i\right|_{s i}=0 \leq\left.\pi_{3} i\right|_{s i}=0, s-i=0=q n h p^{\prime}(0)-1 \leq 0$

and $s^{*}=0$ is the unique solution of Problem 2.4.

( Part 3 )

If $p^{\prime}(0)>1 / n q h$, then $\left.\pi_{s i}\right|_{s i}=0, s-i=0>0$

and $s=0$ does not solve $(2.4)$.

Furthermore, we have

$$
\begin{aligned}
\left.\pi_{s i}\right|_{s i}=h, s^{-i}=h & =-q\left(1-(1+(n-2) p(h))(1-p(h))^{n-1}\right)-1 \\
& <0
\end{aligned}
$$

and $s=h$ does not solve ( 2.4 ) either.

Now, a necessary and sufficient condition for an interior solution is that

$$
\left.\pi_{\mathbf{s}} \mathrm{i}\right|_{\mathbf{s}} \mathrm{i}=\mathbf{r i}=0
$$


Since $\partial / \partial s^{-i}\left\{\left(1+(n-2) p\left(s^{i}\right)\right)\left(1-p\left(s^{i}\right)\right)^{n-2}\right\}$

$$
=-(n-1)(n-2) p\left(s^{-i}\right) p^{\prime}\left(s^{-i}\right)\left(1-p\left(s^{-i}\right)\right)^{n-3}<0
$$

and

$$
\begin{aligned}
\pi_{s^{i}} s^{-i}= & -q(n-1) p^{\prime}\left(s^{i}\right)\left(i-p\left(s^{i}\right)\right)^{n-1} \\
& -q(n-1)^{2}\left(h-s^{-i}\right) p^{\prime}\left(s^{i}\right) p^{\prime}\left(s^{i}\right)\left(1-p\left(s^{-i}\right)\right)^{n-2} \\
& +q\left\{\left(1-p\left(s^{i}\right)\right)+\left(h-s^{i}\right) p^{\prime}\left(s^{i}\right)\right\} \\
& \quad . \partial / \partial s^{-i}\left\{\left(1+(n-2) p\left(s^{-i}\right)\right)\left(1-p\left(s^{-i}\right)\right)^{n-2}\right\} \\
< & 0
\end{aligned}
$$

it follows from the Implicit Function Theorem that

$\partial s^{i} / \partial s^{i}<0$

and there can be at most one interior solution.

Q.E.D.

The preceding proposition states a condition for entry to be an equilibrium, which amounts to say, by Inequalities 2.7 and 2.8, that an entrepreneur will allocate some resources to the innovation race if the marginal benefit is greater than the marginal cost at the point where no resource is allocated to the opportunity search.

Indeed, in general, the first term of ( 2.5$)$ is the marginal monopoly rent. The second is the marginal gain in the technological rent which comes from the increased 
probability of the entrepreneur being able to raise the productivity of his own resources by making a discovery. The third term is the marginal loss in the technological rent due to reduction in the entrepreneur's resources left for production were the competitive process to provide him with new technological knowledge. The fourth, and final, term is the marginal loss in sure output, which is also due to the reduction in the entrepreneur's resources left for production. In Inequalities 2.7 and 2.8 , then, the term $q(n-1) h p^{\prime}(0)$ is the marginal monopoly rent; the term $\mathrm{q} h \mathrm{p}^{\prime}(0)$, the marginal technological rent; and, finally, the terr' -1 , the marginal loss in sure output.

Furthermore, Proposition I indicates that the representative entrepreneur will either not enter the innovation race or diversify his activities by allocating some resources to research and some to production. Since there cannot be any rent in production when no resource is left for production, $\left(s^{i}=h, s^{-i}=h\right.$ ) cannot be an equilibrium as ( 2.9 ) shows.

Finally, the market equilibrium has natural comparative static properties, namely

\section{Proposition II}

If $p^{\prime}(0)>1 /$ nqh, then $\partial s^{*} / \partial q>0$ and $\partial s^{*} / \partial h>0$.

\section{Proof}

Immediate. 
Better opportunities, or the availability of more resources, lead to the allocation of more resources to the search for an innovation. 


\subsection{The Equilibrium of the Large Competitive Economy}

In the preceding section, we have studied the nature of market equilibrium when there is a finite number of representative entrepreneurs. For macroeconomic analysis, it is pertinent to study the behaviour of the economy when the number of entrepreneurs becomes arbitrarily large. In order that the limiting economy make sense, however, we must take care, not only to let the number of agents grow, but also to give each of them the appropriate scale. Since we are concerned with individual innovations whose consequences are not limited to one particular industry but have an aggregate impact, we naturally want the capacity of an agent to make a discovery to become smaller as the number of agents in the economy becomes larger.

Let us, therefore, define

$f_{n}(s)=$ def $f(s) / n$

Where $f(s)$ satisfies all the restrictions we imposed in Section 2 on the probability function p.

Define also $E_{n}$ to be the economy determined by $n, q, h$ and $f_{n}$ in the model of Section 2. The large economy $E$ is then defined as the limit of the sequence of finite economies $\left\{E_{n}\right\}$.

Now, the objective of a representative agent $i$ in the small economy $E_{n}$ is 


$$
\begin{aligned}
\pi_{n}\left(s^{i}, s^{-i}\right)= & q(n-1)\left(h-s^{-i}\right)\left(f\left(s^{i}\right) / n\right)\left(1-f\left(s^{-i}\right) / n\right)^{n-1} \\
+ & q\left(h-s^{i}\right)\left\{\left(f\left(s^{i}\right) / n\right)+\left(1-f\left(s^{i}\right) / n\right)\right. \\
& \left(1-\left(1-f\left(s^{-i}\right) / n\right)\right)^{n-1} \\
& \left.\left.\left.\quad-(n-1)\left(f\left(s^{-i}\right) / n\right)\left(1-f\left(s^{-i}\right) / n\right)\right)^{n-2}\right)\right\} \\
+ & \left(h-s^{i}\right)
\end{aligned}
$$

so that, by construction, the nbjective of a representative entrepreneur in the large economy $\mathrm{E}$ is

$$
\begin{aligned}
\Pi\left(s^{i}, s^{-i}\right)= & \operatorname{dim} \pi_{n}\left(s^{i}, s^{-i}\right) \\
& n \rightarrow \infty \\
= & q\left(h-s^{-i}\right) f\left(s^{i}\right) \exp \left(-f\left(s^{-i}\right)\right) \\
& +q\left(h-s^{i}\right)\left(1-\exp \left(-f\left(s^{-i}\right)\right)-f\left(s^{i}\right) \exp \left(-f\left(s^{-i}\right)\right)\right) \\
& +\left(h-s^{i}\right)
\end{aligned}
$$

A Symmetric Nash Equilibrium $\mathbf{s}^{*}$ in $\mathrm{E}$ will then solve the following problem

$$
\begin{aligned}
s= & \text { ARG MAX } \Pi\left(s^{i}, s\right) \\
& 0 \leq s^{i} \leq h
\end{aligned}
$$

We will show that the limiting process is well defined so that the equilibrium of the large economy is the limit of the sequence of equilibria of the finite economies. 


\section{Proposition III}

The large economy has exactly one equilibrium $\mathrm{s}^{*}$ which is such that

$$
s^{*}=\lim _{n \rightarrow \infty} s_{n}^{*} \text {. }
$$

where $s_{n}^{*}$ is the equilibrium of the small economy $E_{n}$

If $f(0) \leq 1 / q h$, then $s^{*}=0$. If $\Gamma(0)>1 / q h$, then $s^{*}$ is interior.

\section{Proof}

By an argument similar to the one we gave in the proof of Proposition 1, we may show that there exists one and only one $\mathrm{s}^{*}$ which solves Problem 2.12. Furthermore, $\mathrm{s}^{*}=0$ if $f(0) \leq 1 / q h$ and $s^{*}$ is interior if $f(0)>1 / q h$. What remains to be proved is thus that $\mathbf{s}^{*}=\lim \mathbf{s}_{\mathbf{n}}^{*}$.

$$
n \rightarrow \infty
$$

When $f^{\prime}(0) \leq 1 / q h$, the proof is trivial. Assume therefore $f^{\prime}(0)>1 / q h$. Then $s^{*}$ will satisfy

$$
G(s)=0
$$

where

$$
G(s)==_{\text {def }} \prod_{s i}\left(s^{i}=s ; s^{i}=s\right)
$$




$$
=q(h-s) \Gamma(s) e^{-f(s)}+q(1+f(s)) e^{-f(s)}-1-q
$$

Now', $s_{n}^{*}$ satisfies

$G_{n}(s)=0$

where

$G_{n}(s)=\operatorname{def} \partial \pi_{n}\left(s^{i}=s ; s^{-i}=s\right) / \partial s^{-i}$

$$
\begin{aligned}
= & (h-s) \Gamma(s)(1-f(s) / n)^{n-2} \\
& -(h-s)\left(f(s) \Gamma(s) / n^{2}\right)(1-f(s) / n)^{n-2} \\
& +(1+f(s))(1-f(s) / n)^{n-1} \\
& -(2 f(s) / n)(1-f(s) / n)^{n-1} \\
& -1-1 / q
\end{aligned}
$$

so that, for a fixed s,

$\lim G_{n}(s)=G(s)$

$n \rightarrow \infty$

and the sequence $\left\{G_{n}\right\}$ converges pointwise to $G$ on $[0, h]$. Since it is a sequence of continuous and, by 2.10 , monotonic real-valued functions converging to a continuous function, the convergence is uniform. See Dieudonne [1979, Section 7.2, exercise 3].

Choose, then, any $e>0$. By the uniform convergence of $\left\{G_{n}\right\}$ on $\left[s^{*}+e, h\right]$, there exists a $N_{1}$ such that, for any $n \geq N_{1}$, 
$\left\|G_{n}-G\right\|<\left|G\left(s^{*}+e\right)\right| / 2$

which implies

$\mathrm{s}_{\mathrm{n}}^{*}<\mathrm{s}^{*}+\mathrm{e}$

A similar argument show's there exists a $N_{2}$ such that, for any $n \geq N_{2}$,

$s_{n}^{*}>s^{*}-e$

It follow's that, for any $n \geq \max \left\{N_{1}, N_{2}\right\}$,

$s^{*}-e<s_{n}<s^{*}+e$

i.e. $\lim \mathbf{s}_{\mathbf{n}}=\mathbf{s}^{*}$

$n \rightarrow \infty$

Q.E.D.

The comparative static properties of the equilibrium of the large economy are then given by

Proposition IV

$\partial \mathrm{s}^{*} / \partial \mathrm{q}>0$ and $\partial \mathrm{s}^{*} / \partial \mathrm{h}>0$ 


\section{Proof}

Immediate. 


\subsection{Lone-run Growth and the Cycle}

In the preceding sections, we have shown how, within any period, the relative potential improvement in technology $q$ and the quantity of available resources $h$ jointly determine the quantity of resources s allocated to opportunity seeking. As the allocation of resources, in turn, determines the probability a discovery will occur and, ultimately, the probability distribution of output, the respective laws of motion of resource allocation, technology and output can be inferred from the initial technology, the law of motion of the relative potential improvement in technology and the law of motion of the available resources.

When we specified the model in Section 2, we assumed each generation inherited the best technological knowledge of the preceding period, that is

$$
\begin{aligned}
\mu_{\mathrm{a}, \mathrm{t}} & =\mu_{\mathrm{s}, \mathrm{t}-\mathrm{l}} & & \text { when a discovery has occurred in period } \mathrm{t}-1 \\
& =\mu_{\mathrm{a}, \mathrm{t}-\mathrm{l}} & & \text { otherwise }
\end{aligned}
$$

To simplify matters, we will assume also that the quantity of resources available stays constant over time, that is

$$
\mathbf{h}_{\mathbf{t}}=\mathbf{h}, \quad \text { for all } \mathbf{t}
$$

The quantity of resources $s_{t}$ allocated to the exploration of opportunities in period $t$ is then determined by

$$
\mathbf{s}_{\mathbf{t}}=\mathbf{S}\left(q_{\mathbf{t}}\right)
$$


where the functional relation $\mathrm{S}$ is given implicitly by Equation 2.13 .

Also, the probability distribution of the parameter $\mu_{1}$ of the linear production function in period $t$ is

$$
\begin{aligned}
\mu_{t} & =\left(1+q_{t}\right) \mu_{t-1} & & \text { with probability } 1-\exp \left(-f\left(s_{t}\right)\right) \\
& =\mu_{t-1} & & \text { with probability } \exp \left(-f\left(s_{0}\right)\right)
\end{aligned}
$$

Finally, the probability distribution of output is given by

$$
y_{t}=\mu_{t}\left(h-s_{t}\right)
$$

Imposing some structure on the stochastic process governing the relative potential improvement in technology, it is possible to use the model for statistical predictions. For instance, if we assume the potential improvements in technology $q_{t}$ to be identically equal to q over time, we have that

$\log y_{t}=a_{0}+\log y_{t-1}+a_{1}$

where

$$
\begin{aligned}
& a_{0}={ }_{\text {def }} \log (1+q)(1-\exp (-f(s)) \\
& a_{1}=\operatorname{def} \log (1+q)-a_{0} \quad \text { with probability }(1-\exp (-f(s)) \\
& -a_{0} \\
& \text { with probability } \exp (-f(\mathbf{s}))
\end{aligned}
$$

In the language of time series analysis, $e_{t}$ is a white noise process and the log of output follows a random walk with drift. Our model is thus crudely compatible with the 
empirical evidence of Nelson and Plosser [1982] and Campbell and Mankiw [1987].

Our model does not only provide an explanation of the fluctuations in output, it also provides an interpretation of the downtums. Indeed, once we allow the potential improvements in technology $q_{1}$ to vary over time, we can see a downtum in output will be the consequence of the increased allocation of factors to innovation in the face of an "increased opportunity" ex ante, the consequent reduction in the allocation of factors to production, and the failure of the entrepreneurs to innovate ex post which leaves the technique of production as it was. Note that we mean by an increased opportunity a state where, prior to the innovation race and conditional on any given factor allocation, the expected rate of productivity growth is higher.

Indeed, if there is an increase in the opportunity $q_{t}$ from one period to the next, Proposition IV implies that more resources will be allocated to opportunity seeking and, as a consequence, less will be available for production. If, furthermore, the entrepreneur, are not successful in their attempt to innovate, the production technology will remain the same and, as the quantity of inputs has been reduced, output will fall. Better prospects lead to worse conditions if the individuals do not succeed at exploiting them. Since, by Proposition IV again, a lesser or equal relative potential improvement in technology will result in at least as many resources being allocated to production with a technology that is at least as productive, the condition that opportunities improve and entrepreneurs fail to exploit them is both necessary and sufficient for a fall in output.

Some readers may find the preceding result puzzling. Indeed, research can be seen as a particular form of investment and, were our model to be similar to one-sector model of capital accumulation with random productivity, we would expect consumption to fall, but not output, as there would be more investment. However, such an analogy is 
misleading because the research output is not valued by anyone when no discovery occurs and, therefore, no economic investment takes place. To put it another way, a better analogy would be to compare our model to a model of capital accumulation with three sectors : one consumption good, one valuable capital good and one valueless capital good, which capital good is produced being determined only after saving has taken place. In such a set-up, it is clear that were more saving to occur, there would be more investment only in the event of a good draw, the production possibility frontier moving inwards in the event of a bad draw. Similarly, it is misleading to be concerned with the remuneration received by the factors allocated to opportunity seeking unless one remembers it is not independent of the remuneration received by the other factors, an instance of the principle of accounting according to which the national income is the same whether measured by the remunerations of the factors or by the total production. Since technical knowledge is an intermediate product, we use the latter, and simpler, method.

Now, Kydland and Prescott [1982] explain the fluctuations in output with a series of exogenous technological shocks and interpret the downturns as outcomes of negative shocks and the "Slutzky Effect", a mathematical proposition which says that small random shocks may cause an otherwise stable linear difference equation to produce a cycle. The Kydland and Prescott's construction has given rise to two types of criticisms : first, on theoretical grounds, that the shocks may themselves be in need of an economic explanation; and, second, on empirical grounds, that it is hard to think of many instances of the adverse technological shocks which are needed to explain the downturns in output. Such a position is espoused, for instance, in Summers [1986] and Mankiw [1989].

Prescott [1986a] and Plosser [1989] argue, however, that multifactor productivity growth appears to follow an approximate random walk process. Prescott [1986b] also refers to Summers and Heston [1984] as independent evidence that 
productivity growth varies both across and within individual countries over time. Prescott [1986b] then claims, first, that "a theory of technological change is not needed to predict responses to technological change", and, second, that the Slutzky Effect, once the variability of technological change is granted, provides a sufficient explanation of the recessions.

By way of contrast, our model of output fluctuations does rely on a theory of technological change. It predicts technological shocks will occur as outcomes of an innovation process which is intrinsically uncertain and, like Kydland and Prescott's, that the variability of technological change will cause productivity growth to fluctuate. However, the shocks in our model are such that the technology never regresses and the example of Equation 2.20, which pictures a world where output never falls, shows that the fluctuations in productivity growth do not provide, by themselves, a sufficient explanation of the recessions. The real business cycle models may thus capture part of the truth and still fail to explain the recessions. Indeed, Prescott [1986a,b] and Plosser [1989] claim the models have good, but not perfect fit.

Furthermore, our model proposes an explanation of the downturns which is more plausible empirically than to assert that output falls because the techniques of production regress, namely that output falls because fewer faciors produce with the existing techniques Now, the magnitude of the downturns is thence limited by the proportion of factors seeking opportunities and, even though the variable is more general than $R$ \& $D$, as, for instance, a baker trying to improve his cakes is actually seeking opportunities, the proportion is likely to be small. The event that opportunities improve and entrepreneurs fail to exploit them should thus be regarded as an impulse mechanism and a complete explanation would also require a propagation mechanism to amplify the initial reduction in employment and production, just as the real business cycle 
models require a propagation mechanism to amplify their shocks.

Finally, it is interesting to note that under the simplest hypothesis which allows for output to fall, that is when the potential improvements in technology $q_{1}$ are identically and independently distributed, the log of output follows a process with two unit roots. Indeed, once the current realization of $\mathrm{q}_{\mathrm{t}}$ is known to the entrepreneurs, $\mathrm{s}_{\mathrm{q}}$ is determined according to Equation 2.17. It then follows from 2.18 and 2.19 that

$\Delta \log y_{t}=a+x_{t}-x_{t-1}+a$

where $a$ is a constant which, for $k=1, \ldots, t, \ldots, \infty$, is given by

$a=$ def $E_{k-1}\left[\log \left(1+q_{k}\right)\left(1-\exp \left(-f\left(s_{k}\right)\right)\right]\right.$

and where

$$
\begin{aligned}
& x_{t}=\operatorname{def} \log \left(h-s_{t}\right) \\
& a_{1}=\operatorname{def} \log \left(1+q_{t}\right)-a \quad \text { with probability }\left(1-\exp \left(-f\left(s_{t}\right)\right)\right. \\
& \text {-a with probability } \exp \left(-f\left(s_{v}\right)\right.
\end{aligned}
$$




\subsection{Conclusion}

In the present chapter, we have expounded a simple model of our Schumpeterian conception of the long-run growth and business cycle as consequences of the actions of entrepreneurs who seek, find and exploit the profit opportunities which arise out of process innovations.

Our model has three main positive implications. First, the log of output follows a process with random walk characteristics, a result which makes our approach at least crudely compatible with the empirical evidence of Nelson and Plosser [1982] and Campbell and Mankiw [1987]. Second, the technological change process is variable and its variability causes the rate of productivity growth to fluctuate, as Prescott [1986] argues in his Defence of the Real Basiness Cycle research programme. However, those fluctuations do not, by themselves, imply the occurrence of any recession, a result which both provides a counter-example to Prescott's claim that they constitute a sufficient explanation of the downturns, and may also explain why he finds that the Real Business Cycle models have good, but not perfect, fit. Third, and finally, a downturn in output is the consequence of the reallocation of factors in the face of an "increased opportunity" ex ante and of the failure by the entrepreneurs to exploit the opportunity, a result which provides an alternative to the Kydland and Prescott's [1982] explanation of downturns by negative shoiks on technology.

We have made no claims as to the realism of the hypotheses we imposed. Our model should be considered as a prototype, whose purpose is to show the possibility and illustrate our theory of economic dynamics. Further research is thus required in order to improve upon our construction. 
Among the many avenues of improvement which can be taken, we develop, in the next chapter, the endogenous growth aspect of our theory and present a model of an infinite-horizon multisector economy without aggregate uncertainty. 


\section{Eoolnotes}

1. Mention should be made of the Segerstrom et al. [1990] model of the product life cycle. In their work, an endogenous rate of product innovation is determined as the outcome of a sequence of patent races which occur in one sector at a time. Those races are of the Loury [1979] or Dasgupta and Stiglitz [1980] type in that there will be a unique winner and that any firm's probability of winning is a function of the ratio of its own research effort to the industry's. They do not study the implications of their model for the long-run growth and the business cycle.

2. For simplicity, we use, throughout the text, the masculine form to designate a generic agent. The reader may, of course, mentally substitute the feminine form if it makes him or her more comfortable.

3. The reader will note that it would be equivalent to assume $\mu_{\mathrm{s}}$ to be the expected value of a random variable whose distribution is independent of the agent's choice variable. Our framework is thus compatible with fluctuations arising out of "signal extraction problems" Our formulation is meant to emphasize that, under our approach, their existence does not depend upon expectation errors. 


\section{ON THE MULTIPLICITY OF ENDOGENOUS GROWTH RATES}

\subsection{Introduction}

Recent research has produced many models where a coordination failure results in multiple, Pareto-ranked, equilibria. Diamond [1982], for instance, shows that, in the presence of transaction costs, a reciprocal externality arises in connection with the intensity of search, while Hart [1982], Weitzman [1982] and Bryant [1983] show respectively how imperfect competition, increasing returns and imperfect information can produce aggregate spillovers. Cooper and John [1988] survey the coordination failure models and also present an integrative framework.

The coordin stion failure models, so far, have been mostly static in nature and concerned with the possibility of multiple equilibrium rates of unemployment or underemployment, rather than being dynamic and concerned with the possibility of multiple equilibrium rates of growth. Exceptions are Bryant [1987], Kiyotaki [1988] and Weil [1989] who have respectively used imperfect information, imperfect competition and increasing returns to investment to show the possibility of coexistence of a pessimistic and an optimistic equilibrium in two-period one-good models assuming a representative agent. Also, Murphy, Shleifer and Vishny [1989] have a two-period multisector model where a similar multiplicity of equilibria appears because of the profit spillovers associated with an increasing returns production technology. Finally, Azariadis and Drazen [1990] and Fung and Ishikawa [1989] have built threshold models where whether an economy grows or not depends upon whether it initially has or not some critical mass of the appropriate resource, i.e. capital, education, etc.. Until recently, however, no paper had studied the 
possibility of a multiplicity of stationary growth rates in an infinite-horizon endogenous growth economy. (1)

In the preceding chapter, we introduced a simple aggregative model where long-run growth and output fuctuations arose as consequences of Schumpeterian competition. Our model followed Romer [1986] in having endogenous technological change as the source of growth. A crucial difference, however, was that, while Romer assumed the process of knowledge acquisition to be deterministic, we took it to be intrinsically uncertain and com : atble only with a framework where rents could be created and destroyed. A relatc 1 model was developed in Aghion and Howitt [1989].

The present paper extends our previous work and expounds a model of a multisector economy whose dynamics proceed from the actions of entrepreneurs who seek, find and exploit the profit opportunities which arise out of process innovations. We assume the process of knowledge acquisition to be intrinsically uncertain, the probability of a discovery depending positively on the resources used without ever being equal to one, and we assume the evolution of the market structures to depend on its outcome. Furthermore, we assume the decisions of the entrepreneurs on the allocation of their resources between the exploitation of the current production possibilities and the search for better ones to be revised and implemented at the beginning of every period and we assume the discoveries during a period to become innovations only in the next period, so that, within the period, the dynamic stochastic game reduces to a general equilibrium framework. We take the latter to be of the Walras-Bertrand type, with a specification inspired by Shleifer's [1986], i.e. logarithmic preferences and constant retums to scale. Unlike Shleifer's though, our model allows an arbitrary and endogenous number of innovations in any sector within a period, as well as variable and endogenous supplies of factors of production and rates of technological progress over time.(2) 
What comes out is that, for some parametrisations of our model, there exist multiple stationary equilibria associated with different rates of balanced growth. Two kinds of positive spillovers across sectors in the economy contribute to that multiplicity : the Shleifer [1986] effect and a new one which may be called the real income effect.

As Shleifer [1986] noted, in a Walras-Bertrand multisector economy with logarithmic preferences and constant returns to production, a firm's profitability increases with the proportion of firms holding a monopoly position. Now, in our model, the latter proportion in a given period increases with the market allocation of resources to opportunity seeking during the preceding period, provided that allocation is below some critical value. It follows that, in the economy we describe, there may be positive profit spillovers across sectors over the appropriate range of allocations.

Besides the Shleifer effect, our model also reveals the existence of a "real income effect". Indeed, it follows from the assumptions of our model that, eventually, the competitive process will pass on to the consumers, through lower real prices, the benefits arising from the innovations. Now, the more research there is, the more innovations there will be and, therefore, the lower the eventual real prices. Since, in particular, an entrepreneur's potential rent will thereby be made more valuable ceteris paribus ( the "real income effect"), the effect will tend to be self-reinforcing and increase the market allocation of resources to research. 


\subsection{The Model}

Consider an economy populated by a continuum [0, A] of identical agents whose objective is to maximize the expected value of a discounted sum of single-period utilities. At the beginning of every period, each agent is endowed with and has to allocate a quantity $h$ of resources. He may choose to exploit the current production possibilities and supply some of his resources as factors of production. He may also decide to engage in entrepreneurial activity and use some of them to search for the better opportunities an innovation upon the current technological knowledge would confer him. Formally, an agent's resource constraint is therefore

$h=l_{1}+s_{1}$

$l_{1}$ denoting the resources supplied as factors of production ( "labour" ) and $s_{t}$ the resources allocated to entrepreneurial activity.

Were any entrepreneur to be successful and make a discovery, he would, at the end of the period, be able to embed his technological knowledge in a firm and thereby modify the production sector of the economy from the next period onwards. His innovation would then have been transformed into property rights in the (potential) profit of the firm he created, the profit being naturally defined as the residual which appears once all factors of production have been remunerated. Of course, the profit would not only depend upon the process innovation per se, but also upon the context of its occurrence, i.e. upon whether or not and in which sectors other innovations have occurred, as well as upon what the consumers' preferences and the structures of the markets are. 
We assume that the firms, which embody the techniques of production, and the market structures during a period are determined as of the end of the preceding period and that, after one period, imitation always destroys profits. We assume also that no physical storage is possible so that, within a period, what is produced is consumed. Since the decisions on the allocation of resources between production and entrepreneurial activity are assumed to be made at the beginning of every period, the analysis of what happens afterwards during any period can then be carried out within the categories of a suitable general equilibrium framework. In order to accommodate the endogenous market structures, we will take the latter to be of the Walras-Bertrand type.

\subsubsection{Consumption}

We assume that, within a period, the preferences of each and every agent are represented by a current period utility functional, taken to be of the logarithmic form, over the continuum of goods $[0,1]$. Such a preference structure admits perfect aggregation and the consumption side of the economy reduces, therefore, to a representative consumer. Assuming no physical storage is possible and denoting by $y_{1}$ his income, the representative consumer's single-period decision problem is

$\operatorname{MAX} \exp \left(\int_{[0,1]} \log x_{r}(i) d i\right)$

s.t. $\int_{[0,1]} \operatorname{pr}(i) \lambda_{1}(i) d i=y_{t}$

where $p_{r}(i)$ and $x_{(}(i)$ are respectively the price and the quantity consumed in period $t$ of $\operatorname{good} \mathrm{i}$.

It follows that the consumer will spread his income as a uniform now of 
expenditures over the goods; i.e.

$$
p_{t}(i) x_{t}(i)=y_{t}
$$

Furthermore, the indirect momentary utility functional can be written explicitly as a mapping linear in $y_{b}$ i.e.

$$
\begin{aligned}
v\left(p_{t}, y_{t}\right) & =y_{t} / \exp \left(\int_{\{0,1\}} \log p_{t}(i) d i\right) \\
& ={ }_{\operatorname{def}} b\left(p_{t}\right) y_{t}
\end{aligned}
$$

and the cost-of-living index can be shown to depend upon relative prices only, i.e.

$$
I\left(p_{t+1}, p_{t}\right)=\exp \left\{\int_{[0,1]} \log \left(p_{t+1}(i) / p_{t}(i)\right) d i\right\}
$$

The indirect intertemporal utility functional is thus

$$
\sum_{j=0, \ldots, \infty} \mathfrak{B j}^{j} y_{i+j} / \exp \left(\int_{[0,1]} \log p_{t+j}(i) d i\right)
$$

where $B=(1 /(1+r))$ and $r>0$ is the constant rate of time preference.

\subsubsection{Production}

Within a period, the production side of the economy is made of single-product firms grouped by sectors. Any firm, regardless of its sector, uses only one factor of 
production, "labour". In each and every sector, firms have access to a production technology in which the marginal product of labour is a parameter that depends upon technological knowledge and may vary from firm to firm. We assume every firm in sector $i$ to have access to the knowledge, embodied in a parameter $\mu_{v}(i)$, which corresponds to the most efficient production technique used in the preceding period, while some firms may or may not have access to an innovation embodied in a parameter $\mu_{\text {ts }}(i)$ ( $\left.\mu_{t s}(i)>\mu_{\mathrm{ta}}(\mathrm{i})\right)$. We assume that, from the perspective of a given firm, its current parameter value is exogenous.

While we assume the market for labour to be perfectly competitive and, without loss of generality, normalize the wage to 1 so as to make labour the numeraire, we assume the markets for goods to be ruled by firms engaging in Bertrand price competition. In any sector, three cases are then possible.

First, a firm may have a monopoly over the new technological knowledge in its sector ( $i$ ), i.e. its production function is :

$x_{n}(i)=\mu_{t s}(i) l_{t}(i)$

while its competitors' is :

$x_{r}(i)=\mu_{t a}(i) l_{t}(i)$

Now, the mass of consumers being A times the mass of goods, the market demand function is given by :

$P_{n}(i) x_{r}(i)=A Y_{1}$ 
$Y_{1}$ being the average income in the economy.

Since the demand function is unit elastic, it follows that the firm will price its output at the marginal cost of its less efficient competitors, i.e.

$p_{1}(i)=1 / \mu_{t a}(i)$

and serve the whole market.

Its profit, equal to the total profit in the sector, will then be

$$
\begin{aligned}
\pi_{k}(i) & =p_{f}(i) x_{t}(i)-l_{t}(i) \\
& =\left(1-l_{n}(i) /\left[p_{r}(i) x_{t}(i)\right]\right) A Y_{t} \\
& =\left(1-\mu_{t a}(i) / \mu_{t s}(i)\right) A Y_{t} \\
& =(q(i) /(1+q(i))) A Y_{t}
\end{aligned}
$$

where $q(i)$ is defined to be such that :

$\mu_{t s}(i)=(1+q(i)) \mu_{t a}(i)$

and is interpreted as the relative improvement in technology.

The second possibility is that two firms, at least, have access to the new technological knowledge. In that case, each will price its output at its marginal cost and earn thereby zero profits; i.e.

$P_{r}(i)=1 / \mu_{s s}(i)$ 
and the total profit in the sector is :

$\pi_{r}(i)=0$

Finally, it is possible that there won't be any firm having access to the innovation. Each firm will then price its output at its marginal cost and earn zero profits; i.e.

$p_{k}(i)=1 / \mu_{b}(i)$

and the total profit in the sector is :

$\pi_{(i)}=0$

Now, the average income in the economy is equal to the sum of the average labour income $L_{1}$ and the average dividend income $D_{1}$; i.e.

$$
\begin{aligned}
Y_{t} & =L_{t}+D_{t} \\
& =\left(H-S_{t}\right)+\int_{[0,1]} \partial_{r}(i) \pi_{r}(i) d i / A \\
& =\left(H-S_{t}\right) /\left\{1-\int_{[0,1]} \partial_{r}(i)\left[q_{r}(i) /\left(1+q_{r}(i)\right)\right] d i\right\}
\end{aligned}
$$

where $H$ and $S_{t}$ are respectively the average endowment and the average allocation of resources to opportunity seeking, and where $\partial_{t}$ is defined to be such that $\partial_{t}(i)=1$ if there is a monopoly in sector $i$ and 0 otherwise. 
Assuming $q_{r}(i)$ to be constant over sectors and equal to $q_{t}$ we find that

$Y_{t}=\left(1+q_{t}\right)\left(H-S_{t}\right) /\left(1+\left(1-m_{t}\right) q_{t}\right)$

and the profit in any monopolistic sector is given by

$\pi_{\mathrm{t}}=A q_{t}\left(H-S_{t}\right) /\left(1+\left(1-m_{t}\right) q_{t}\right)$

where $m_{t}$ is defined by

$m_{\uparrow}=\operatorname{def} \int[0,1] \partial_{l}(i) d i$

and represents the proportion of sectors in the economy where a firm has a monopoly position.

\subsubsection{Entrepreneurship and Resource Allocation}

Having specified in the preceding paragraphs the structure of the economy within a period, we can now expound its intertemporal structure. We assume that, at the beginning of every period, each individual has the possibility to seek a process innovation in one sector, $\mathbf{A}$ individuals facing an opportunity in any given sector. The learning process is, however, uncertain and the probability of a discovery by a given individual is a function $f$ of the resources $s$ allocated to opportunity seeking by that individual. We also assume that the individual discoveries are independent events and that the function $f$ is of class $\mathrm{C}^{2}$ and satisfies $\mathrm{f}(0)=0, \mathrm{f}(\mathrm{s}) \geq 0, \mathrm{f}(\mathrm{s})<1, \mathrm{f}^{\prime}(\mathrm{s})>0$ and $\mathrm{f}^{\prime \prime}(\mathrm{s})<0$. Furthermore, we assume that the individuals are identical with respect to their learning abilities, so that both 
the relative opportunity and the probability function of its occurrence are the same not only for each and every one of them in any given sector, but also across sectors as well. Finally, we assume the probability function to be constant over time.

Since we assumed a continuum of goods, what will matter for any agent is only the potential effect his resource allocation may have on his income, the potential effect on the price of one good being negligible. Now, with potential relative improvements in technology constant across sectors, the potential ex post rewards to entrepreneurship are constant as well, and with identical learning processes across sectors, their ex ante distributions, conditional on the economy's resource allocation, are the same. It follows that, under our assumptions, all entrepreneurs will face an equivalent problem, i.e. the dynamic game is symmetric.

We will assume that, in order to decide upon his resource allocation, an entrepreneur takes as given the decisions of his competitors and the decisions of all individuals in the other sectors, i.e. the game is solved for a Nash equilibrium. Furthermore, we will consider only representative entrepreneu. equilibria, i.e. symmetrical Nash equilibria. It follows that we will only have to take into account two types of variables : the entrepreneur's and the market's. We will use lower case letters for the former and capital letters for the latter.

\subsubsection{Industrial Organization and the Dynamics of Prices}

Under our many symmetry assumptions, we can easily characterize the industrial organization and the dynamics of prices in the model. Since, from the perspective of a representative entrepreneur whom we assume $w$ be active in sector $j$, we 
have that, for $i \neq j$,

$\partial_{f}(\mathrm{i})=1 \quad$ with probability $\mathrm{A} f\left(\mathrm{~S}_{\mathrm{t}-1}\right)\left(1-\mathrm{f}\left(\mathrm{S}_{\mathrm{t}-1}\right)\right)^{\mathrm{A}-1}$

$=0$ with probability $1-A f\left(S_{t-1}\right)\left(1-f\left(S_{t-1}\right)\right)^{A-1}$

it follows from Definition 3.19 that

$m_{t}=A f\left(S_{t-1}\right)\left(1-f\left(S_{t-1}\right)\right)^{A-1}$

Also, since it does not depend upon a measure zero change, we can take the distribution of prices to be independent of the representative entrepreneur's own resource allocation, i.e.

$p_{t} \sim G\left(p_{t} \mid p_{t-1} ; q_{t-1}, q_{t}, S_{t-2}, S_{t-1}\right)$

where

$$
\begin{aligned}
& p_{1}(i)=\left(1 /\left(1+q_{t-1}\right)\right) p_{t-1}(i) \quad \text { with probability } m_{t-1}\left(1-c_{t}\right) \\
& =\left(1 /\left(1+q_{t}\right)\right) p_{t-1}(i) \quad \text { with probability }\left(1-m_{t-1}\right) c_{t} \\
& =\left(1 /\left(1+q_{1}\right)\right) \\
& .\left(1 /\left(1+\sigma_{t-1}\right)\right) p_{t-1}(i) \quad \text { with probability } m_{t-1} c t \\
& =\mathrm{p}_{\mathrm{t}-1}(\mathrm{i}) \quad \text { with probability } \\
& \left(1-m_{t-1}\right)\left(1-c_{t}\right)
\end{aligned}
$$

$\mathfrak{c}_{\mathrm{t}}$, which represents the proportion of sectors where multiple discoveries occur during period $t$, being defined as 
$\mathrm{C}_{\mathrm{t}}=$ def $1-\operatorname{Af}\left(\mathrm{S}_{\mathrm{t}-1}\right)\left(1-\mathrm{f}\left(\mathrm{S}_{\mathrm{t}-1}\right)\right)^{\mathrm{A}-1}-\left(1-\mathrm{f}\left(\mathrm{S}_{\mathrm{t}-1}\right)\right)^{\mathrm{A}}$

Indeed, the probability that, in any given sector $i$, an innovation with monopoly in period t-1 will be followed by either an innovation with monopoly or by no innovation at all in period $t$ is $m_{t-1}\left(1-c_{t}\right)$. Now, we have from Equations 3.9, 3.11 and 3.14 that

$p_{t-1}(i)=1 / \mu_{t-1, a}(i)$

$p_{k}(i)=1 / \mu_{t, a}(i)$

and

$\mu_{t, a}(i)=\mu_{t-1, s}(i)=\left(1+q_{t-1}\right) \mu_{t-1, a}(i)$

so that, in such a case,

$P_{r}(i)=\left(1 /\left(1+q_{t-1}\right)\right) p_{t-1}(i)$

The three other cases follow by analogous reasoning.

Finally, we have that the distribution of the entrepreneur's dividend $d_{l}$ is

$d_{t} \sim F\left(d_{t} \mid q_{t} ; s_{t-1}, s_{t-1}, s_{t}\right)$

where

$d_{t}=\pi_{t}$ with probability $f\left(s_{t-1}\right)\left(1-f\left(S_{t-1}\right)\right)^{A-1}$

$=0$ otherwise 


\subsection{The Representative Entrepreneur's Problem}

From what precedes, we can write the representative entrepreneur's problem as

$\operatorname{MAX} E_{t} \Sigma_{j}=0, \ldots, \infty \beta i v\left(p_{t+j}, y_{t+j}\right)$

s.t.

h $=I_{t+j}+s_{t+j}$

$y_{t+j}=I_{t+j}+d_{t+j}$

$p_{t+j} \sim G\left(p_{t+j} \mid p_{l+j-1} ; q_{t+j-1}, q_{t+j}, S_{t+j-2}, S_{t+j-1}\right)$

$d_{l+j} \sim F\left(d_{l+j} \mid q_{l+j} ; s_{l+j-1}, S_{t+j-1}, S_{l+j}\right)$.

At time $t$, ihe past and current values of all the variables, as well as the value of $q_{t+1}$, belong to the information set of the entrepreneur. So does the $\left\{S_{i+i}\right\}_{i=0, \ldots \infty}$ sequence, since, under the Nash Assumption, the entrepreneur takes it as given.

Now, by Definitions 3.3 and 3.4,

$$
\begin{aligned}
b\left(p_{t+1}\right) & =\operatorname{der} \exp \left(-\int_{[0,1]} \log p_{t+1}(i) d i\right) \\
& =\exp \left(-\int_{[0,1]} \log p(i) d i\right) \cdot \exp \left(-\int_{[0,1]} \log \left(p_{i+1}(i) / p(i)\right) d i\right) \\
& =b(p) / 1\left(p_{t+1}, p_{t}\right)
\end{aligned}
$$

and, by Equations 3.21a to 3.21d

$\int[0.1] \log \left(p_{t+1}(i) / p_{1}(i)\right) d i=\log \left(1 /\left(1+q_{t}\right)\right) \cdot m_{t}+\log \left(1 /\left(1+q_{i+1}\right)\right) \cdot c_{i+1}$ 
so that

$I\left(p_{t+1}, p_{t}\right)=\left(1 /\left(1+q_{t}\right)\right)^{m_{t}}\left(1 /\left(1+q_{t+1}\right)\right)^{c_{t+1}}$

and it follows that the cost-of-living indexes, and thereby the marginal utilities of income, are deterministic aggregates.

Assuming a solution exists and is interior, the current resource allocation $s_{\imath}$ is determined by the first order condition

$$
\begin{aligned}
b\left(p_{t}\right) & =B \partial / \partial s_{t} E\left\{b\left(p_{t+1}\right) y_{t+1}\right\} \\
& =B b\left(p_{t+1}\right) \partial E d_{t+1} / \partial s_{t}
\end{aligned}
$$

where

$\partial \mathrm{Ed}_{t+1} / \partial s_{t}=\pi_{t+1} \Gamma\left(s_{\imath}\right)\left(1-f\left(S_{\jmath}\right)\right)^{A-1}$

Naturally, the interpretation of the condition is that an optimal current resource allocation will equalize the marginal utility of current income to the present value of the expected marginal utility of next period dividend income.

Now, we have that the equation may be written equivalently as

$1=B\left(\partial E d_{t+1} / \partial s_{1}\right) / I\left(p_{t+1}, p_{t}\right)$

an equation whose interpretation is that the representative agent's resource allocation will equalize, in real terms, his current wage with the present value of his expected marginal 
dividend.

Yet another interpretation may be given, as the entrepreneur's problem is both a problem of intertemporal resource allocation and a problem of intertemporal consumption decision. Indeed, the allocation of resource to research may be thought of as an investment in a stochastic asset whose rate of return will vary with the state of the world, the probability of oscurrence of any particular event depending both upon the entrepreneur's action and the market's.

Equation 3.26 may then be rewritten as

$\left(1 /\left(1+q_{t}\right)\right)^{m_{t}}\left(1 /\left(1+q_{t+1}\right)\right)^{c_{t+1}} / B$

$=\left\{A q_{1+1}\left(H-S_{t+1}\right) /\left(1+\left(1-m_{1+1}\right) q_{1+1}\right)\right\} \Gamma\left(s_{2}\right)\left(1-f\left(S_{i}\right)\right)^{A-1}$

The left-hand-side of the equation is the marginal rate of substitution between consumption at time $t$ and at time $t+1$, while the right-hand side is the marginal rate of return of investing in research. The equation may thus be interpreted as saying that investment will equalize the marginal rate of substitution of present and future consumption to the marginal return of investment.

The preceding equation also embodies the many different channels th:rough which the market resource allocations $S_{t-1}, S_{t}$ and $S_{t+1}$ influence the representative agent's $s_{1}$. By Equations 3.20 and $3.22, m_{t}$ is a function of $S_{t-1}$ only while $c_{t+1}$ is a function of $S_{t}$ only. Equation 3.28 may thus be rewritten as

$F\left(s_{i} ; S_{1-1}, S_{1}, S_{1+1}\right)=0$ 
where

$$
\begin{aligned}
F=\operatorname{def} & B\left\{A q_{t+1}\left(H-S_{t+1}\right) /\left(1+\left(1-m_{t+1}\right) q_{t+1}\right)\right\} f\left(s_{t}\right)\left(1-f\left(S_{l}\right)\right)^{A-1} \\
& -\left(1+q_{t}\right)^{m_{l}}\left(1+q_{t+1}\right)^{c_{t+1}}
\end{aligned}
$$

Since $f^{\prime \prime}\left(s_{1}\right)<0$, we have then

$\partial \mathrm{F} / \partial \mathrm{s}_{\mathrm{t}}<0$

and it follow's that, for $k=t-1, t, t+1$, the effect of an $S_{k}$ on $s$ has the same sign as $\partial F / \partial S_{k}$

Now, the $S_{k}$ 's have five different effects on $s_{t}$. The left-hand side equation in (3.28) embodies two of those : the effect which the allocation made last period has on the price index next period, and the effect which the current allocation has on the same index. The former, which we may call the lagged real income effect is associated with the $\left(1 /\left(1+q_{t}\right)\right)^{m_{t} t e r m . ~ I t ~ i s ~ d u e ~ t o ~ t h e ~ t r a n s m i s s i o n, ~ t h r o u g h ~ p r i c e s, ~ o f ~ t h e ~ b e n e f i t s ~}$ arising from the innovations made in monopolistic sectors with a one period lag, as imitation destroys the rents and diffuses the gains to the consumers. The latter, which we may call the contemporaneous real income effect is associated with the $\left(1 /\left(1+q_{t+1}\right)\right) c_{t+1}$ term. It is due to the immediate transmission to the consumers, through Bertrand price competition, of the benefits arising from simultaneous innovations in competitive sectors. The net result of the lagged and contemporaneous real income effects may be called the net real income effect.

Now, we have 
$\partial c_{t+1} / \partial S_{t}=A(A-1) f\left(S_{t}\right) \Gamma\left(S_{t}\right)\left(1-f\left(S_{J}\right)\right)^{A-2}>0$

Since more resources spent on research now means an increase in the rate at which real prices will fall next period, and since lower real prices make the dividend income, measured in units of labour, more valuable, ceteris paribus the spillovers arising from the contemporaneous real income effect are unambiguously positive and there is, in the terminology of Bulow, Geanakoplos and Klemperer [1985], a strategic complementarity between the market resource allocation $S_{1}$ and the representative agent's as an increase in the former induces the agent to raise his own allocation.

On the other hand, we have

$\partial m_{1} / \partial S_{1-1}=A f\left(S_{1-1}\right)\left(1-f\left(S_{t-1}\right)\right)^{A-1}\left(1-A f\left(S_{t-1}\right)\right)$

and the lagged real income effect is ambiguous as it will be positive for the allocations $S_{1-1}$ below the critical value $S^{C}$ and negative for the allocations above, $S^{C}$ being defined as the root of $(1-A f(S))$ if it exits and $S^{C}={ }_{\text {def }} \infty$ otherwise.

What happens is that when past research activity $\mathbf{S}_{\mathrm{t}-1}$ gets beyond the critical value $\mathrm{SC}$, the proportion of monopolistic sectors starts to decrease and the benefits of the innovations are transmitted to the consumers in the current period to a greater extent rather than being "accumulated". Ceteris paribus, the real prices will then fall at a slower pace next period, so that the market allocation $S_{1-1}$, which is a relative complement for the representative agent's $\mathrm{s}_{\mathrm{t}}$ when $\mathrm{S}_{\mathrm{l}-1}<\mathrm{S}^{\mathrm{C}}$, becomes a strategic substitute when $\mathrm{S}_{\mathrm{t}-1}>\mathrm{SC}^{\mathrm{C}}$.

From what precedes, whether the net real income effect is positive or not 
depends upon $S_{t-1}, S_{t}, q_{t}$ and $q_{t+1}$. When the entrepreneur's environment is stationary, however, that is when $q_{1}=q_{t+1}$ and $S_{t-1}=S_{t}$, we have

$$
\begin{aligned}
& \partial / \partial S_{t}\left(m_{t}+c_{1}\right)=\partial / \partial S_{1}\left(1-\left(1-f\left(S_{\nu}\right)^{A}\right)\right. \\
& =A f\left(S_{\mathcal{U}}\left(1-f\left(S_{\mathcal{J}}\right)\right)^{A-1}>0\right.
\end{aligned}
$$

Since, in th- case, the benefits arising form the innovations are transmitted to the consumers at a uniform rate over time, and since, in the long run, more research can only increase the rate at which real prices are falling, the market resource allocations $S_{t-1}$ and $S_{t}$ are then net strategic complements to the representative agent's $\mathbf{s}$.

The right-hand side of ( 3.28 ) embodies three different effects which, besides the real income effects, influence the entrepreneur's decision. The first, which we may call the Shleifer effect, is associated with the denominator of the equation, through the dependence of $\mathrm{m}_{\mathrm{t+1}}$ on $\mathrm{S}_{\mathrm{t}}$. The second, which we may call the competition effect, is associated with the $\left(1-f\left(S_{t}\right)\right)^{A-1}$ term. Finally, the third, which we may call the aggregate demand effect, is associated with the $\left(H-S_{t+1}\right)$ term.

As we showed earlier, for every market allocation $S_{1}$ below the critical value $S^{c}$, a bigger allocation means a greater proportion of monopolistic sectors in the economy. Beyond, it means a lesser proportion. Since the potential profit depends positively on the proportion of monopolistic sectors through the original Shleifer [1986] effect, our version of the effect will be ambiguous and the current market allocation $S_{1}$ will provide a positive (negative) spillover and be a strategic complement ( substitute) to the representative agent's if it is smaller ( larger) than the aforementioned critical value.

Now, we have that an increase in the level of research activity carried on by his 
competitors reduces both the probability and the marginal probability of a monopolistic innovation by an entrepreneur. The competition effect, therefore is unambiguous, as the competitors' effort provides a negative spillover and is a strategic substitute for the representative agent's.

Finally, as more resources spent on research next period means a lower aggregate demand by then and, thereby, lesser profits, th: aggregate demand effect is unambiguously negative.

Assuming a market equilibrium exists, it will then satisfy both the first order condition and the equality

$\mathbf{s}_{\mathrm{t}}=\mathbf{S}_{\mathrm{t}}$

Finally, a stationary equilibrium is defined as one where the solution is stationary. 


\subsection{The Multiplicity of Stationary Equilibria}

Consider now a stationary environment, i.e. one where $q_{t}=q$ for all $t$. From the first order and equilibrium conditions, a stationary equilibrium $\mathbf{s}$ will satisfy the equation

$(1 / 1+q)^{m+c}=B D \Gamma(s)(1-f(s))^{A-1}$

where

$D=A q(H-s) /(1+(1-m) q)$

$m=A f(s)(1-f(s))^{A-1}$

and

$c=1-A f(s)(1-f(s))^{A-1}-(1-f(s))^{A}$

Given the presence of at least one and, under some conditions, two channels through which the market allocation is a strategic complement to the entrepreneur's, the question which naturally arises is whether or not there are conditions, i.e. parametrisations of the model, under which those effects are strong enough to dominate and lead to multiple stationary equilibria. The answer is provided in the following proposition. 


\section{Proposition V}

There exist at least one parametrisation of the model such that there are multiple stationary equilibria.

\section{Proof}

Let $f(s)$ be given by $f(s)=1-e^{2 s}$

where $a=$ def $(1+q) / B$ A qH

Then, by construction, we have

LHS $\left.\right|_{s=0}=1=$ RHS $\left.\right|_{s=0}$

so that $s=0$ is an equilibrium

Now, we have also

$$
\begin{aligned}
\partial / \partial s \text { LHS }\left.\right|_{s=0} & =\log (1 /(1+q)) . A \text { a } \\
& =-[(1+q) \log (1+q)] / B q H \\
& <0
\end{aligned}
$$

and 
$\partial / \partial s$ RHS $=\{A q B /(1+(1-m) q)\}$

$$
\begin{aligned}
.\left\{(H-s) f^{\prime \prime}(s)(1-f(s))^{A-1}-f(s)(1-f(s))^{A-1}\right. \\
-(A-1)(H-s) f^{(2)}(s)(1-f(s))^{A-2} \\
\left.+ \text { RHS } f^{\prime}(s)(1-f(s))^{A-2}(1-A f(s))\right\}
\end{aligned}
$$

so that

$$
\text { d/2s RHS } \begin{aligned}
\left.\right|_{s=0} & =\{A q B /(1+q)\}\left\{-H a^{2}-a \cdot(A-1) H a^{2}+(a / B)\right\} \\
& =\{A q B a /(1+q)\}\{-1-A H a+(1 / B)\} \\
& =-[1 / H][1+(1 / B q)] \\
& <0
\end{aligned}
$$

and

$\partial / \partial s$ RHS $\left.\right|_{s=0}=>\partial / \partial s$ LHS $\left.\right|_{s=0}$

if and only if

$B<\{(1+q) \log (1+q)-1\} / q$

Since

LHS $\left.\right|_{s=H}=(1 /(1+q))^{1 \cdot(1-f(H))^{A}} \quad>0 \quad(3.42)$,

and 
RHS $\left.\right|_{\mathbf{s}=\mathbf{H}}=0$

it follows, by a continuity argument, that, provided ( 3.41 ) holds, there exists at least one $s^{\dagger} \neq 0$ such that

LHS $\left.\right|_{s=s} \dagger=$ RHS $\left.\right|_{s=s} \dagger$

i.e. there exist at least one $\mathrm{s}^{\dagger} \neq 0$ which is an equilibrium.

Q.E.D.

Though, for simplicity, we have picked a case where one equilibrium is at $s=0$ and at least another one is interior, our construction could easily be modified so as to lead to a comer equilibrium at $s=0$ and multiple interior equilibria. Indeed, we can see from Figure 1 that, provided

LHS $\left.\right|_{s=0}>$ RHS $\left.\right|_{s=0}$

the two curves will intersect an even number of times generically. Such will be the case if and only if

A q H $\mathrm{r}^{\prime}(0) /(1+q)<1 / B$

An example where Inequality 3.44 is satisfied is then provided by lowering slightly the value of $B$ in the proof of Proposition V. 
Now, if we define the gross rate of return as

$R\left(s_{t} ; S_{t}, S_{t+1}\right)={ }_{\text {def }} E d_{t+1} / s_{t}$

we have, by L'Hospital Rule,

$R(0 ; 0)=A q H r(0) /(1+q)$

Also, if we define the Marginal Rate of Intertemporal Substitution as

$\operatorname{MRIS}\left(S_{t-1}, S_{t}\right)==_{\text {def }}\left[(1 /(1+q))^{m_{t}+q_{t+1}}\right] / B$

we have

$\operatorname{MRIS}(0)=1 / B$

It follows that ( 3.41 ) can be written equivalently as

MRIS $\left.\right|_{S=0}>R(0 ; 0)$

a condition formally similar to the one given by Weil [1989; Prop. 2] in the context of a two-period one-good consumption model which assumed the existence of a representative agent as well as external increasing returns to investment.

Indeed, Weil's model may be interpreted as an approximation to the two-period version of the reduced model obtained by the exact aggregation of the consumption side of 
ours, provided that the aggregate consumption good therein is measured in utility terms rather than with respect to a numeraire, that the capital stock and the endowments are respectively defined in terms of foregone and potential utility, and that, finally, the rate of returns refers to the intertemporai utility trade-off.

Under the preceding interpretation, the translation of our analysis of the representative agent's decision problem is that, as long as the Shleifer and the real income effects dominate the competition and the aggregate demand effects, the potential intertemporal utility trade-off of the representative entrepreneur will improve with the market allocation of resources to research. What Weil's model fails to take into account, however, is that the "endowments" are affected by the aggregate level of "investment", the current one being unambiguously reduced by the aggregate demand effect and the future ones being eventually increased by the real income effect.

Note that our construction shows that, when it is measured in terms of the numeraire, which, in the present context, is "labour", the rate of return does not '.ave to be increasing for there to be multiple equilibria, because a strong enough real income effect is, by itselt, sufficient. Note also that both the Shleifer and the real income effects are features of a multisector economy which cannot be analyzed in a one-good model.

Besides its mathematical simplicity, the case we presented also allows a simple link with the result of Murphy, Shleifer and Vishny [1989] who model a switch from pre-industrialization to industrialization as a move from a bad to a good equilibrium. They obtain a multiplicity of equilibria by allowing any firm to choose between a constant and an increasing retums technology of production, the latter not being profitable for a firm to adopt by itself, but being profitable if various sectors of the economy adopt increasing returns technologies simultaneously. 
While their model is basically a one-shot game where the coordination failure arises because of externalities in exogenously given technologies, we are able, by endogenising the technology, to dispense with the static increasing retums assumption and obtain, in a framework otherwise quite similar to theirs, a dynamic generalization of their result by showing the possibility of multuple growth rates in general and, in particular, the possibility of coexistence, as stationary equilibria of the same cconomy, of a zero and a positive growth rate. This has some importance because, while the Shleifer effect, which is at the root of their result, relies on a peculiar assumption of non-convexity and can thus be criticized as a figment of the specification, the real income effect occurs because an innovator can never fully appropriate the benefits which his innovation generates, a feature which casual empiricism show's to pertain to any actua' economy. 


\subsection{Robustness}

Having constructed an example of multiple equilibria, we may wonder how general a phenomena it represents. One possible way to answer the question is to study its robustness, that is to study whether or not the multiplicity will remain when we perturb slightly the structure of the model.

Since the whole construction relied, for its tractability, on the snecific preference structure we assumed, it is not possible to study within our framework the robustness of our example with respect to the preference structure. It is, however, easy to show its robustness with respect to a change in the production or innovation structure.

Indeed, the multiplicity of equilibria is equivalent to the multiplicity of roots on $[0, h]$ of $z(s ; A, q, h, f)$, where

$z(s ; A, q, h, f)=\operatorname{def}(1 / 1+q)^{m+c}-B D \Gamma(s)(1-f(s))^{A-1}$

D, $\mathrm{m}$ and $\mathrm{c}$ bcing respectively defined in $3.33,3.34$ and 3.35 .

Now, provided the values of the parameters $A, q, h$ and $f$ are such that 3.44 is met, we will have $z(0)>0$ and $z(h)>0$ and it is obvious that the curve which is the graph of $z$ will still have multiple roots when a small change in the parameters perturbs it slightly ( Sec Figure 2).

An example where 3.44 is satisfied, finally, is obtained by lowering slightly the valuc of $B$ in our proof of Proposition $V$. 


\subsection{Conclusion}

In the second chapter, we expounded a model of a one-good economy where long-run growth and output fluctuations are endogenous consequences of the decisions taken by entrepreneurs on the allocation of their resources between production and innuvation in a Markovian sequence of one-period games. We showed, first, that the log of output follows a process with random walk characteristics; second, that the variability of the technological change process causes the rate of productivity growth to fluctuate, bu: that those fluctuations do not imply, by themselves, the occurrence of any recession; third, and finally, that a downturn in output is the consequence, not of a Kydland and Prescotts [1982] negative shock on technology, but of the reallocation of factors in the face of an "increased opportunity" ex ante which the entrepreneurs fail to exploit ex post

In the current chapter, we developed a model of an infinite-horizon multisector economy where growth is endogenous and results from the actions of entrepreneurs who seek, find and exploit the profit opportunities which arise out of process innovations. We studied the potential coordination failures and showed that, at least for some parametrisations of the model, there exist multiple stationary equilibria associated with different rates of growth. We also identified the effects which are at the root of the multiplicity, namely the Shleifer effect and the real income effect. Finally, we provided an interpretation of our results.

Having now constructed two models of the Schumpeterian growth process and explored their positive properties, we may wonder about their normative implications. Indeed, we may wonder if their respective equilibria are efficient and, when not, if the competitive process involves an overinvestment or an underinvestment in innovation, i.e. if the rate of growth is higher or lower than efficiency would warrant. 
Those are topics we treat in the next, and final, chapter. 


\section{Footnotes}

1. There exists a multiplicity of equilibria in the Shleifer [1986] model, but only one of them is stationary.

Also, the possibility of multiple steady state equilibria is noted, but not explored, in Segerstrom, Anant and Dinopoulos [1987] who construct a Schumpeterian model of the product life cycle. The note is not reproduced in the published version of their work [1990].

Finally, Greenwald and Stiglitz [1989] have a model where the equity level of a firm constraints its level of output. Assuming productivity growth is driven by learning-by-doing and learning-by-doing is proportional to output, they show that there may be a multiciplicity in the level of output and the rate of growth when there are ( static) increasing returns to scale in production. As the reader will see in due course, there is no binding equity constraint in our model, production is made under ( static ) constant returns to scale and the multiplicity is caused by a dynamic phenomena : real prices which fall over time.

2. A similar framework has been developed independently by Grossman and Helpman [1991] in a continuous-time framework. Their w'ork does not bear on coordination failures, however. Furthermore,they treat an innovation as the intreluction of a new good of higher quality rather than as a reduction in the cost of productiol. of an already existing good and they are not, therefore, able to identify the "real income effect" which, as we shall see, turns out to play an important role. 


\section{ENDOGENOUS GROWTH AND WELFARE}

\subsection{Introduction}

An Arrow-Debreu economy has the property that any of its Walrasian equilibria is a Paretian outcome, so that the equilibrium can be found as a solution to an appropriate optimisation exercise. When a representative agent is assumed, the procedure is not only possible, but also mathematically convenient, and it is, therefore, often used in the New Classical Macroeconomics literature.

One may wonder at the meaning of a welfare maximisation exercise, generally and equirocally designated as the "Central Planner's Problem", which involves an omniscient, omnipotent and benevolent deity. Though we will in the sequel pursue our analysis in the traditional fashion, it is worthwhile pointing out, lest the reader misinterprets us and derives inappropriate implications for policy, that, interpreted as a positive model of government behaviour, the Central Planner's Problem assumes away the issues raised by the actual objectives of the government officials(1), as well as the information and incentive requirements of effective intervention in the economy. Indeed, a lot of ambiguity would be removed if, instead of the "Central Planner's Problem", one was to speak of the "Paretian Problem".

Properly understood, the point of the welfare maximization exercise is twofold. First, it may be considered to be a useful technical artifice. Indeed, as it is generally much easicr to solve the Central Planner's Problem than the Walrasian system of equations, the equivalency of the two problems in a Robinson Crusoe economy where the conditions of 
the first and second theorems of welfare economics are met makes the Central Planner's Problem a mathematically simple procedure to find the set of equilibria. Second, and most importantly, it provides a benchmark against which various possibilities may be assessed. In particular, and for purposes of positive analysis, one can compare the set of competitive ouicomes to the set of Paretian solutions and thereby obtain indirect insights about how the market process solves its information and coordination problems and about how gains from trade are perceived and realized.

Since the two models we have built are not Walrasian, their competitive equilibria do not have to be Paretian outcomes, and their welfare properties have to be studied from scratch. As the two models differ in their salient features, their respective studies will allow us to focus on the capacity of the inarket process to handle different types of externalities. The model of Chapter 2, indeed, refers to a one-good economy with a succession of generations which do not overlap, while the model of Chapter 3 pictures a multisector economy with infinitely lived agents. Though in both models the intertemporal diffusion of knowledge eventually leads to higher real incomes, the knowledge spillover creates an externality across generations in the former nodel, while it creates several externalities across contemporaneous agents in the latter model. Finally, though simultaneous discoveries may occur in both models, the potential replication of discoveries in the one existing sector tend to make the innovations net substitutes in the former model, while the occurrence of simultaneous discoveries in different sectors tend to make the innovations net complements in the latter model. We will proceed first with the welfare analysis of the model introduced in Chapter 2. 


\subsection{The One-Good Economy}

Let us consider the large one-good economy of Chapter 2. As it is not Walrasian, we cannot assume its equilibrium to be efficient and its welfare properties have to be studied from scratch. Now, our model involves a succession of generations and spillovers arise both within and across generations. Across generations, because the knowledge produced by the research effort of one generation is a free good to all future generations. Within any generation, because the action of an individual entrepreneur affects the welfare of the other agents through three different channels : First, ceteris paribus any increase in his allocation of resources to innovation will reduce the probability someone else will have a monopoly on the new technological knowledge; Second, it will reduce the amount of resources at the disposal of an eventual rentier and, therefore, the magnitude of the potential rent; Third, and finally, it will increase the probability that, through multiple discoveries and Bertrand price competition, the technological knowledge and its associated rent will diffuse to those agents who will not have made a discor'ery by themselves. Clearly, the latter spillover is positive; the former two, negative.

In that context, two notions of efficiency can be relevant. First, in a restricted way, we may study whether or not the one-period economy is contemporaneously efficient. That is, we may study whether or not any generation could unilaterally make itself better off by deviating from the market equilibrium. Second, in a broader sense, we can study whether or not the dynamic economy is intertemporally efficient. That is, we can study whether or not any generation could be made better off without reducing the welfare of any other generation.

Let us begin with the study of the contemporaneous efficiency of the 
one-period economy. To proceed, we will use a standard procedure in the analysis of symmetric games and take as our benchmark the Symmetric Cooperative Solution of the innovation race, the Symmetric Cooperative Solution being defined as the symmetric allocation which maximizes the welfare of the representative player.

Now, in Chapter 2, Section 2, we assumed an agent's utility was given by his expected consumption. Furthermore, we know from ( 2.11 ) that if all agents allocate resources s to innovation, a discovery will occur with probability $1-\exp (-f(s))$, where $f$ is a function of class $C^{2}$ which satisfies $f(0)=0, f(s) \geq 0, f(s)<1, \Gamma(s)>0$ and $f^{\prime \prime}(s)<0$. The reader will also remember from Chapter 2, Sections 2 and 4, that $h$ represents the resource endowment of any individual; $\mu_{\mathrm{a}}$, the parameter of the linear production technology as of the beginning of the period; and $q$, the potential productivity improvement. The Symmetric Cooperative Solution will therefore solve the Problem

MAX E $\mu(h-s)$

$0 \leq \mathbf{s} \leq \mathrm{h}$

$$
\text { where } \begin{aligned}
\mu & =(1+q) \mu_{\mathrm{a}} & & \text { with probability } 1-\exp (-\mathrm{f}(\mathrm{s})) \\
& =\mu_{\mathrm{a}} & & \text { with probability } \exp (-\mathrm{f}(\mathrm{s}))
\end{aligned}
$$

a problem which may also be written as

$\operatorname{MAX} \quad v=(1+q(1-\exp (-f(s)))(h-s)$

$0 \leq \mathbf{s} \leq \mathbf{h}$.

Our first task will be to show the Symmetric Cooperative Solution is well-defined by proving ( 4.2 ) has a solution which is unique. We will also give a 
necessary and sufficient condition for the solution to be interior.

\section{Proposition VI}

The Central Planner's Probiem has a unique solution $s^{C}$. If $f(0) \leq 1 /$ qh, then $s^{C}=0$. If $r(0)>1 / q h$, then the solution is interior.

Prool

By Weierstrass Theorem, ( 4.2 ) has at least one solution.

Since

$$
\partial v / \partial s=q \exp (-f(s)) f^{\prime}(s)(h-s)-(1+q(1-\exp (-f(s)))
$$

we have

$$
\begin{aligned}
\hat{\partial}^{2} \mathrm{v} / \partial \mathrm{s}^{2}= & q \exp (-f(s))\left(f^{\prime \prime}(s)-f^{2}(s)\right)(h-s) \\
& -(1+q) \exp (-f(s)) \Gamma(s) \\
< & 0
\end{aligned}
$$

and the objective function is strictly concave.

The solution is therefore unique.

$$
\text { As } \partial v /\left.\partial s\right|_{s=h}=-(1+q(1-\exp (-f(h)))<0
$$


$s=n$ cannot solve the Problem.

As $\delta v /\left.\partial s\right|_{s=0}=h q r(0)$

$s=0$ will solve the Problem if and only if $\Gamma(0) \leq 1 /$ hq. Otherwise, the solution is interior and satisfies

$$
\begin{aligned}
\partial v / \partial s= & q \exp (-f(s)) \Gamma(s)(h-s) \\
& -(1+q(1-\exp (-f(s))) \\
= & 0
\end{aligned}
$$

Q.E.D.

Thanks to their respective characterizations provided by Equations 2.13 and 4.7, we can compare the Symmetric Nash Equilibrium and the Symmetric Cooperative Solution of the one-period economy. What comes out is that there are more resources allocated to innovation in the competitive equilibrium than in the cooperative solution, i.e. $\mathrm{s}^{\mathrm{C}}<\mathrm{s}^{*}$.

Proposition VII

Any generation could make itself unilaterally better off by reducing its level of research.

Proof

By Equation 4.7, $5^{C}$ satisiies 
$F(s)=0$

(4.8),

where

$F(s)=\operatorname{def} q(h-s) \Gamma(s) e^{-f(s)}-\left(1+q\left(1-e^{-f(s)}\right)\right)$

By Equation 2.13, the market equilibrium $\mathrm{s}^{*}$ satisfies

$G\left(s^{*}\right)=0$

where

$G(s)=\operatorname{der} q \Gamma(s)(h-s) e^{-f(s)}+q e^{-f(s)}+q f(s) e^{-f(s)}-1-q$

Now, we have

$G(s)=F(s)+q f(s) e^{\cdot f(s)}$

so that, for any $s>0$,

$\mathrm{F}(\mathrm{s})<\mathrm{G}(\mathrm{s})$

and, in particular,

$F\left(s^{*}\right)<G\left(s^{*}\right)=0=F\left(s^{C}\right)$ 
Since, by $4.4, F^{\prime}(s)<0$, it follows

$s^{C}<s^{*}$.

Q.E.D.

Because an individual entrepreneur values only the rents he creates for himself and does not care about the rents he destroys, there is, within any generation, a negative externality associated with the potential replication of innovations. The process of Schumpeterian competition, therefore, involves a waste of current resources with respect to the welfare of the current generation, and any generation could make itself unilaterally better off by reducing its level of research. A similar result is standard in the "patent race" literature. See, for instance, Loury [1979, Prop. V]. There, however, it applies to an industry in partial equilibnum, rather than to a generation in temporary equilibrium.

On the other hand, across generations, the free transmission of knowledge means that a generation's research effort provides the generations which follow with a positive externality. Since a higher level of research involves an increased probability of discovery and since, ceteris paribus, the intertemporal diffusion of knowledge provides any generation with a higher rei' income when a discovery has occurred in a previous period, there is a positive intertemporal spillover associated with a generation's research. Were a generation to deviate from the intertemporal equilibrium and make itself unilaterally better off with a reduction in its allocation of resources to research, each subsequent generation would then have to reduce its level of research as well or see its own welfare fall below its equilibrium level. In the former case, however, the compounded rate of growth would fall and it follows that, in either case, some generation would eventually be made worse off. We thus have 


\section{Proposition VIII}

The decentralized outcome is intertemporally efficient.

\section{Proof}

Suppose, by way of contradiction, that the economy is inefficient. Then there exists a sequence of allocations $s^{\circ}=\left\{s_{t}\right\}_{t=1} \ldots \infty$ where $s_{t}$ is generation t's allocation and which is such that at least one generation is better off and no generation is worse off than in equilibrium. That is, defining $V_{t}^{\circ}$ to be the expected utility, as of the initial period, of generation $t$ in the sequence $s^{\circ}$ and $V_{t}^{*}$ to be the expected utility of the same generation in equilibrium, we have, for all $t$,

$$
V_{1}^{0} \geq V_{1}^{*}
$$

with sinct inequality for at least one $t$.

Now, from ( 2.18$)$ and $(2.28)$, we have

$$
V_{i}^{0}=\prod_{1=1 . .1}\left(1+q\left(1-\exp \left(-f\left(s_{i}\right)\right)\right)\left(h-s_{t}\right)\right.
$$

and

$$
V_{1}^{*}=\left(i+q\left(1-\exp \left(-f\left(s^{*}\right)\right)\right)^{\prime}\left(h-s^{*}\right)\right.
$$

Wuinout loss of generdity, we can take the first generation to be better off than in 
equilibrium. By Proposition VII, we have then $s_{1}<s^{*}$. For generation 2 not be made worse off, however, we must have $s_{2}<s^{*}$ as well, whence, by recurrence, $s_{1} \leq s^{*}$ for all $t$. It follows that, for all $t$,

$\left(1+q\left(1-\exp \left(-f\left(s_{j}\right)\right) \leq\left(1+q\left(1-\exp \left(-f\left(s^{*}\right)\right)\right)\right.\right.\right.$

which implies

$V_{t}^{0} \leq\left(1+q\left(1-\exp \left(-f\left(s_{1}\right)\right)\right)\left(1+q\left(1-\exp \left(-f_{i}\left(s^{*}\right)\right)\right)^{t-1}\left(h-s_{t}\right)\right.\right.$

Now, from ( 4.15), (4.17) and (4.19), we have

$\left(1+q\left(1-\exp \left(-f\left(s_{1}\right)\right)\right)\left(h-s_{1}\right) \geq\left(1+q\left(1-\exp \left(-f\left(s^{*}\right)\right)\right)\left(h-s^{*}\right)\right.\right.$

and there exists an $A$ such that $s_{1} \leq A=s^{*}$ for all t. From (4.16), it then follows

$V_{i}^{0} \leq\left(1+q(1-\exp (-f(A)))^{t} h\right.$

and, from ( 4.15 ), ( 4.17 ) and (4.20), we have, for all $t$,

$\left(1+q(1-\exp (-f(A)))^{t} h \geq\left(1+q\left(1-\exp \left(-f\left(s^{*},\right)\right)^{\prime}\left(h-s^{*}\right)\right.\right.\right.$

or, taking logs and rearranging,

$t \leq\left[\log h-\log \left(h-s^{*}\right)\right]$

$/\left[\log \left(1+q\left(1-\exp \left(-f\left(s^{*}\right)\right)\right)-\log (1+q(1-\exp (-f(A)))]\right.\right.$

(4.22), 
a contradiction since the right hand side is a finite number and $\mathrm{t}$ takes any natural value.

Q.E.D.

The intertemporal economy we have described is thus one more case where two externalities with effects working in opposite directions "compensate" one another and make the decentralized outcome efficient. A policy directed at altering the on-going level of research has to be based, therefore, on a willingness to modify the utility trade-off across generations.

Now, there is a popular perception, which one finds expressed in newspapers or scientific magazines, for instance, according to which fundamental research has important, albeit hard to forecast, future benefits. What our construction points out is that, though the mathematics of the Greeks were of use to Kepler, it could hardly have been an incentive for them to produce more unless they were happy to make sacrifices for the sake of posterity. Indeed, they were a ready producing more of it than their own welfare woulc have warranted.

Since the rent-secking aspect of the innovation race leads, per se, to an overinvestment in research, one would have to identify contemporaneous positive spillovers, strong enough to dominate, so as to justify an increase in the research effort on efficienc; grounds. Now, the argument that a discovery made in one particular sector has often general features applicable in other sectors as well would not do it by itself, as a multisector economy where all innovations are perfect substitutes ${ }^{(2)}$ would be a particular case of our one-sector economy and one would expect the so-called spillover to be captured in the rent. 
As we shall see in the next section, an argument can be talade though for the presenc $:$ in a multisector economy of positive contemporancous spillovers which are dominant. It relies, however, not on informational spillovers, but on the existence of several market imperfeciuns which the process of inncvation creates in its wake. 


\subsection{The Multisector Economy}

Let us finally consider the multisector, infinite-horizon and infinitely-lived agerits economy of Chapter 3. Like the one-good economy of Chapter 2, it is not Walrasian. Its equilibrium ( equilibria ), therefore, cannot be assumed to be efficient and we have to study its ( their ) welfare properties from scratch. Indeed, and more specifically, we will first study whether or not the equilibrium allocation of resources is efficient and, then, whether efficiency would be improved by an increase or a decrease in tix allocation of resources to innovation; that is, we will study whether the competitive rate of grow'th is higher or low er than the efficient rate.

In Chapter 3, we uncovered and studied the strategic implications of five extcmalıties, namely : the lagged and contemporaneous real income effects, as well as the competition, aggregate demand and Shleifer effects. Given the presence of those many distortions, it would be rather surprising if anything general could be asserted regarding the welfare properties of the market outcome. Indeed, the results which follow can be summarized by saying they make more precise that impossibility.

Since all agents are alike and infinitely-lived and since the dynamic game is symmetric, we will take, in order to proceed with our welfare analysis, the set of Symmetric Cooperative Solutions as our natural benchmark.

The reader will remember from Chapter 3 that the intertemporal utility functional of any agent is

$\Sigma_{\jmath=0,}, \infty B \exp \left(\int_{[0,1]} \log x_{n}(\mathrm{i}) \mathrm{di}\right)$ 
where $B$ is the constant rate of time preference and $x_{(}(i)$ is the quantity consumed of good $i$ at time $\mathrm{t}$.

Furthermore, any agent has at his disposal resources $h$ to allocate between production ( $h-s)$ and innovation $(s)$. The technologies of production are linear, the parameters relevant in sector $i$ at time $t$ being $\mu_{t s}(i)$ for an innovator and $\mu_{t a}(i)$ otherwise. The individual innovations, occur with probability $f(s)$, where $f$ is function of class $C^{2}$ such that $f(0)=0, f(s) \leq 1, r(s)>0$ and $f^{\prime \prime}(s)<0$. Finally, in any period, there are $A$ potential innovators in any given sector. To make the notation less cumbersome, we will assume $\mathrm{A}=1$ in what follows.

Now, the welfare optimisation exercise may be decomposed in two sub-problems : the intentemporal allocation of resources between production and research and the instantaneous allocation of productive resources. Clearly, the latter will be solved if we assume efficient prices, i.e. if each good is priced at marginal social cost.

From what precedes, together with Equations 3.1 to 3.5 and the fact there is no profit income, a Symmetric Cooperative Solution $\left\{s_{t+j}\right\}_{j=0}, \infty$ will solve

$\operatorname{MAX} W_{t}=E_{1} \sum_{j=0, \ldots, \infty} B_{j}\left(h-s_{t+j}\right) / I\left(p_{t+j}, P\right)$

wherc $I\left(p_{i+j}, p_{i}\right)=\exp \left\{\int_{[0,1]} \log \left(p_{l+j}(i) / p_{t}(i)\right) d i\right\}$

Furthermore, the price dynamics will obey 


$$
\begin{aligned}
\mathbf{p}_{t+j}(i) & =(1 /(1+q)) p_{t+j-1}(i) & & \text { with probability } f\left(s_{t+j-1}\right) \\
& =p_{t+j-1}(i) & & \text { with probability } 1-f\left(s_{t+j-1}\right)
\end{aligned}
$$

so that

$I\left(p_{t+1}, p_{i}\right)=(1 /(1+q))^{f\left(s_{l}\right)}$

and

$I\left(p_{t+\jmath}, p_{U}=\prod_{k=0, \ldots,-1}(1 /(1+q))^{f\left(s_{t+k}\right)}\right.$

We thus obtain

$W_{1}=\Sigma_{j=0}, . \infty \beta j(1+q) \Sigma_{k=0, . j-1} f\left(s_{1+k}\right)\left(h-s_{t+j}\right)$

Let us define now' the state variable $x_{j}$ by

$x_{j}=\sum_{d i f} \quad \sum_{k=0, j-1} f\left(s_{t+k}\right)$

and notice its law of motion is given by:

$x_{j+1}=x_{j}+f\left(s_{t+j}\right)$

The Bellman equation for our dynamic optimisation problem can then be written as 


$$
V(x)=\operatorname{MAX}\left\{(1+q)^{x}(h-s)+B V\left(x^{\prime}\right)\right\}
$$

s

The first order condition is

$-(1+q)^{x}+B V^{\prime}(x+f(s)) f^{\prime}(s)=0$

and the Benveniste-S: iheinkman formula is

$V^{\prime}(x)=(1+q)^{x} \log (1+q)(h-s)+B V^{\prime}(x+f(s))$

Now, using the particular structure of the objective, we can see that

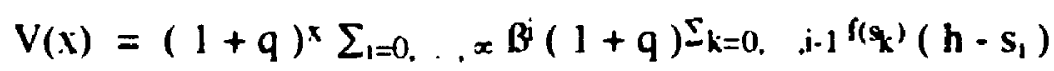

and

$V^{\prime}(x)=V(x) \log (1+q)$

( $4.34 b)$.

Similarly,

$$
V(x+f(s))=(1+q)^{x+f(s)} \sum_{l=0, \ldots \infty} B^{j}(1+q) \sum_{k=0 .} \ldots i-1 f\left(s_{k}\right)\left(h-s_{1}\right) \quad(4.34 c)
$$

and

$$
V^{\prime}(x+f(s))=V(x+f(s)) \log (1+q)
$$


So that

$V(x+f(s))=(1+q)^{f(s)} V(x)$

and

$V^{\prime}(x+f(s))=(1+q)^{f(s)} V^{\prime}(x)$

From :he Benveniste-Scheinkman formula 4.33 and Equation $4.34 f$, we have then

$V^{\prime}(x+f(s))=(1+q)^{f(s)}(1+q)^{x} \log (1+q)(h-s)\left(1-B(1+q)^{f(s)}\right)^{-1}$

and the first order condition 4.32 may be rewritten as

$-(1+q)^{x}+B(1+q)^{f(s)}(1+q)^{x} \log (1+q)(h-s)\left(1-B(1+q)^{f(s)}\right)^{-1} f(s)=0$

or, equivalently,

$B\left\{(1+q)^{f(s)} \log (1+q)(h-s)\left(1-B(1+q)^{f(s)}\right)^{-1} f(s)\right\}-1=0$

an equation whose solution is independent of the state variable $x$.

We have thus proven 


\section{Proposition IX}

The Symmetric Cooperative Solution is a stationary sequence, i.e. $s^{C_{1+j}}=s^{c}$ for all $j \geq 0$, where $\mathbf{s}^{\mathrm{C}}$ is a constiant.

The Paretian Problem is to maximize the present value of the stream of real per capita income. Investing in research, therefore, involves a trade-off between the base of the stream and its rate of growth as the potential production of the resources allocated to research is foregone so as to obtain a faster rate of productivity growth on the remaining resources.

The Problem is best understood, however, when interpreted in capital-theoretic terms ${ }^{(3)}$. Thus stated, it can be seen as the choice of a time-path of research which will produce the knowledge of the highest capital value. Since any factur allocated to opportunity seeking is foregone for production purposes, the Problem involves a trade-off between the accumulation of new capital through the innovation process and the depreciation of the old capital through the reallocation of resources from production to research. For a given allocation, thence, the objective function $\mathrm{W}_{\mathrm{t}}$ may be interpreted as the capital at time t. Likewise, the capital-theoretic interpretation of the optimality condition 4.32 is that the optimal allocation of resources will be such that, in each and every period, the marginal accumulation of new capital will be equal to the marginal depreciation of the existing capital. What Proposition IX tells us, finally, is that, on the optimal path, capital will be accumulated at a constant rate over time.

Knowing implicitly the set of Symmetric Cooperative Solutions from Equation 4.35, we can finally' use it as our benchmark in order to assess the welfare properties of the set of market equilibria. As we mentioned earlier, it would be surprising if, in the 
presence of several externalities, anything general could be asserted. Indeed, it turns out that, depending upon the particular values taken by the parameters, the allocation of resources to innovation may be either too high or too low; that is, efficiency gains may be achieved either through a reduction or an increase in the rate of growth.

\section{Proposition X}

Depending upon the particular values taken by the parameters, the competitive process may lead to ovcrinvestment or underinvestment in research.

\section{Proof}

From the first order condition of the Central Planner's Problem, we can see that $s=0$ will be optimal if

$B<1 /[\log (1+q) \Gamma(0) h+1]$

Now, any market equilibrium will be interior provided

$B>(1+q) / q h f(0)$

The level of research in equilibrium will therefore be too high for the parameter values which satisfy tuth inequalities simultaneously.

Likewise, if

$B>1 /[\log (1+q) \Gamma(0) h+1]$ 
it will be optimal to allocate a strictly positive quantity of resources to research. However, if

$B<(1+q) / q h r(0)$

there will be a market equilibrium at $s=0$.

Under the parameters values which satisfy both inequalities, there will thus be a market equilibrium such that the allocation of resources to research is too low.

Q.E.D.

As it is well known, while one externality causes an inefficiency, many which work in opposite directions can compensate one another In the present context, the contemporaneous real income effect is positive, the Shleifer and the lagged real income effect both ambiguous and the competition and aggregate demand effects both negative. It is therefore not surprising to see the order relation between the compelitive and the benchmark allocation shift as the parameter values change.

Given the economy is inefficient, one may wonder if some government intervention could not improve matters. For this to be the case in a world of imperfect markets and imperfect governments, the intervention would have to bring less inefficiency than it is supposed to eliminate. Now, in the Schumpeterian world we described, a Planner would face terrible informational problems. Indeed, the criteria which allow one to determine whether there is an inefficiency or not ( Inequalities 4.36 to 4.39 ) involve threc unobservable magnitudes : the rate of time preference $\beta$, the marginal probability of a 
discovery $r(0)$ and the potential productivity improvement $q$. One must remember, furthermore, that, although it is an acceptable simplification for theoretical purposes to assume those parameters to be identical across agents and over time, they would vary in a more realistic interpretation.

In order to design an efficient intervention, therefore, a Planner would have, first, to learn somehow the primitives of the system, and, then, to trace out the complex web of distortions and strategic interactions to figure out the net result of his potential actions. In this task, he would face two difficulties. First, an agent will not reveal the private information he has unless he thereby makes himself better off. Second, and most importantly, an agent will not use scarce resources to acquire such information in the absence of adequate incentives. The Planner's process of knowledge acquisition will thus, in all likel:hood, not only provide the Planner with an information more noisy than the private agents', but will also destroy some of their information. Finally, as there is no simple rule to follow, each case would have to be dealt with on a "ad hoc" basis, which means that the knowledge would have to be gathered through large-scale social experimentation. This, of course, would have unknown and unforeseeable consequences.

We suggest, therefore, that the design of an efficiency improving intervention is likely to be an unmanageable task and that a decentralized solution, albeit imperfect, may be as much as one can realistically hope for. On that conjecture, which is also an invitation to further research, it is fit that we now leave our reader. 


\section{Footnotes}

1. A principal-agent problem, in contemporary jargon.

2. Consider the case, say, where all final goods are perfect substitutes and where all innovations improve the productivity of labour in the same proportion.

3. The reader will note that the competitive problem could also have been interpreted in capital-theoretic terms. Such a study would, however, be outside the bounds of the current monograph and is left for a future paper. 
Figure 1

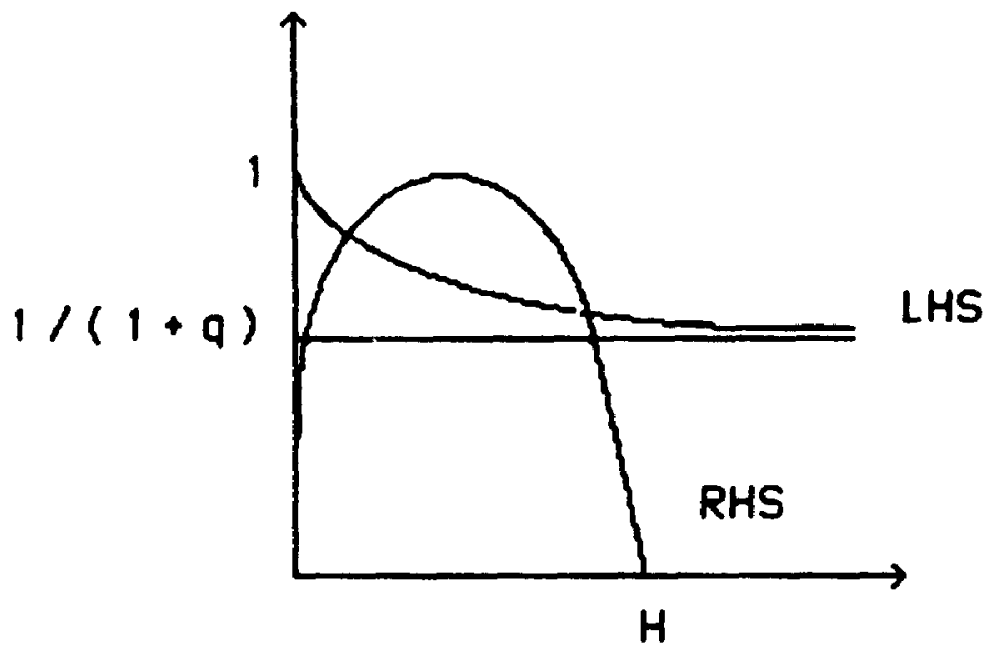


Figure 2

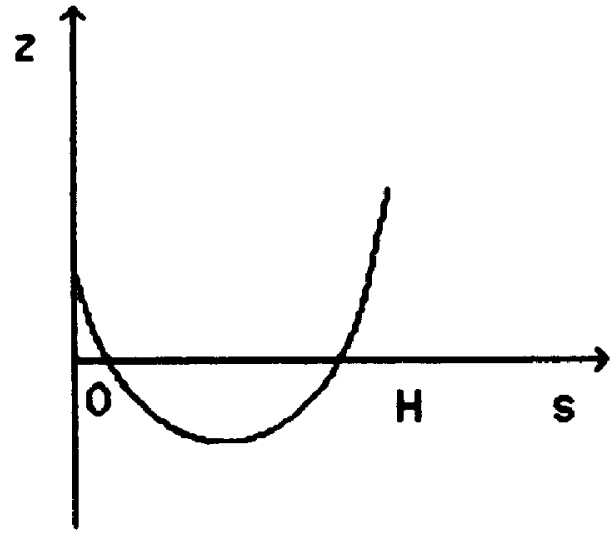


PIIIIINGRAPHY

Aghion, Philippe and Howitt, Peter, "A Model of Growth through Creative Destruction", Unpublished, M.I.T. and University of Western Ontario, May 1989.

Azariadis, Costas and Drazen, Allan, "Threshold Externalities in Economic Development", Quarterly Journal of Economics, Vol. CV, Issue 2, May 1990; pp. 501 526.

Blanchard, Olivier and Fischer, Stanley, Lectures on Macroeconomics, MIT Press, Cambridge 1989.

Bryant, John, "A Simple Rational Expectations Keynes-Type Model", Quarterly Joumal of Economics, Vol. XCVIII, No. 3, August 1983; pp. 525 - 528.

Bryant, John, "The Paradox of Thrift, Liquidity Preference and Animal Spirits", Econometrica Vol. 55, No. 5, September 1987; pp. 1231 - 1235.

Bulow, Jeremy, Geanakoplos, John and Klemperer, Paul, "Multimarket Oligopoly : Strategic Substitutes and Complements", Joumal of Political Economy Vol. 93, No. 3, June 1985; pp. 488 - 511.

Campbell, John and Mankiw, Gregory, "Are Output Fluctuations Transitory ?", Quarterly Joumal of Economics, Vol. CII, Issue 4, November 1987; pp. 857 - 88. 
Cooper, Russell and John, Andrew , "Coordinating Coordination Failures in Keynesian Models", Quarterly Joumal of Economics Vol. CIII, Issue 3, August 1988; pp. 441 - 463.

Dasgupta, Partha and Stiglitz, Joseph, "Industrial Structure and the Nature of Innovative Activity", Economic Joumal, Vol. 90, No. 358, June 1980, pp. 266 - 293.

Debreu, Gérard, Theory of Value Yale University Press, New Haven 1959.

Diamond, Peter ,"Aggregate Demand Management in Search Equilibrium", Journal of Political Economy Vol. 90, No. 5, October 1982; pp. 881 - 894.

Dieudonne, Jean, Éléments d'analyse, Vol. 1, Third edition, Gauthiers-Villars, Paris 1979.

Fung, Michael and Ishikawa, Jota, "Dynamic Increasing Returns, Technology, and Economic Growth in a Small Open Economy", Unpublished, University of Western Ontario, May 1989.

Greenwald, Bruce and Stiglitz, Joseph, "Financial Market Imperfections and Productivity Growth", Working Paper No. 2945, National Bureau of Economic Research, April 1989.

Grossman, Gene and Helpman, Elhanan, "Quality Ladders in the Theory of Growth", Review of Economic Studies, Vol. 58(1), No. 193, January 1991; pp. 43 - 61. 
Hayek, Friedrich, Individualism and Economic Order, University of Chicago Press, Chicago 1948.

Hart, Oliver, "A Model of Imperfect Competition with Keynesian Features", Quarterly Joumal of Economics, Vol. XCVII, No. 1, February 1982; pp. 109 - 138.

Heller, Walter, "Coordination Failure Under Complete Markets with Applications to Effective Demand", in Walter Heller, Ross Starr and David Starrett ( eds. ) Equilibrium Analysis : Essays in Honor of Kenneth J. Arrow, Vol. 11, Cambridge University Press 1986; pp. 155 - 175.

Howitt, Peter , "Transaction Costs in the Theory of Unemployment", American Economic Review Vol. 75, No. 1, March 1985; pp. 88 - 100.

King, Robert and Rebelo, Sergio, "Business Cycle with Endogenous Growth", Unpublished, University of Rochester, February 1989.

King, Robert etal., "Production, Growth and Business Cycles : I. The Basic Neoclassical Model", Joumal of Monetary Economics, Vol. 21, No. 2-3, March/May 1988, pp. 195 - 232.

King, Robert et al. "Production, Growth and Business Cycles : II. New Directions", Joumal of Monetary Economics, Vol. 21, No. 2-3, March/May 1988, pp. $309-341$. 
Kiyotaki, Nobuhiro ,"Multiple Expectational Equilibria Under Monopolistic Competition", : larterly Journal of Economics, Vol. CIII, Issue 4, Nov. 1988; pp. 695 713.

Kydland, Finn and Prescott, Edward, "Time to Build and Aggregate Fluctuations", Econometrica Vol. 50, No 6, November 1982, pp. 1345 - 1370.

Laidler, David, "The Austrians and The Stockholm School : Two Failures In The Development of Modern Macroeconomics? ", Unpublished, University of Western Ontario, July 1987.

- Lee, Tom and Wilde, Louis, "Market Structure and Innovation : A Reformulation", Quarterly Journal of Economics, Vol. XCIV, No. 2, March 1980; pp. 429 - 436.

Long. John and Plosser, Charles, "Real Business Cycles", Joumal of Political Economy. Vol. 91, No. 1, February 1983, pp. 39-69.

Loury, Glenn, "Market Structure and Innovation", Quarterly Journal of Economics, Vol. XCIII, No. 3, August 1979, pp. 395 - 410.

Lucas, Robert, Studies in Business-Cycle Theory MIT Press, Cambridge, 1981.

Lucas, Robert, "On the Mechanics of Economic Development", Journal of Monetari Economics, Vol. 22, No. 1, July 1988; pp. 3 - 42. 
Mankiw, Gregory, "Real Business Cycles : A New Keynesian Perspective", Journal of Ecunomic Perspectives, Vol. 3, No. 3, Summer 1989; pp. 79 - 90.

Marshall, Alfred, Principles of Economics, Eight Edition, Macmillan, London 1920.

Mill, John Stuart, Principles of Political Economy [1871], reproduced as Vo!. II, III and IV of the Collected Works, University of Toronto Press 1965.

Murphy, Kevin, Shleifer, Andrei and Vishny, Robert, "Industrialization and the Big Push", Journk., of Political Economy, Vol. 97, No. 5, October 1989; pp. 1003 1026.

Nelson, Charles and Plosser, Charles, "Trends and Random Walks in Macroeconomic Time Series", Journal of Monctary Economics, Vol. 10, No. 2. September 1982, pp. 139-162.

Plosser, Charles, "Understanding Real Business Cycles”, Joumal of Economic Perspectives, Vol. 3, No. 3, Summer 1989; pp. 51 - 77.

Pollack, Robert, "The Theory of the Cost-of-Living Index", in W.E. Diewert and C. Montmarquette ( editors ), Brice Level Measurement, Statistics Canada, Ottawa 1983, pp. 87- 161.

Prescott, Edward, "Theory Ahead of Business Cycle Measurement", Quarerly Review Federal Reserve Bank of Minneapolis, Vol 10, No.4, Fall 1986a; pp. 9 - 22. 
Prescolt, Edward, "Response to a Skeptic", Quarterly Review, Federal Reserve Bank of Minneapolis, Vol 10, No.4, Fall 1986b; pp. 28 - 33.

Reinganum, Jennifer, "Practical Implications of Game Theoretic Models of $\mathbf{R}$ \& D", American Economic Review ( Papers and Proceedings ), Vol. 74, No. 2, May 1984; pp. $61-66$.

Reinganum, Jennifer, "The Timing of Innovation : Research, Development, and Diffusion", chap. 14 in Richard Schmalensee and Robert Willing (editors), Handbook of Industrial Organization. Vol. I, North-Holland 1989; pp. 849 - 908.

Roberts, John, “An Equilibrium Model with Involuntary Unemployment at Flexible, Competitive Prices and Wages", American Economic Review Vol. 77, No. 5, December 1987; pp. $856 \cdot 874$.

Romer, Paul, "Increasing Returns and Long-Run Growth", Joumal of Political Economy Vol. 94, No. 5, October 1986, pp. 1002 - 1037.

Romer, Paul, "Endogenous Technological Change", Journal of Political Economy Vol. 98, No. 5 Part 2, October 1990; pp. S 71 -S 102.

Rowe, Nicholas, “A Simple Macroeconomic Model with Monopolistic Firms”, Economic Inquiry, Vol. XXV, No. 1, January 1987; pp. 83 - 102.

Schumpeter, Joseph, The Theory of Economic Devciopment, Harvard University Press, Cambridge 1934 ( English translation of the 1911 German original ). 
Segerstrom, Paul, Anant, T.C.A. and Dinopoulos, Elias, “A Schumpeterian Model of the Product Life Cycle", Unpublished, Michigan State University, May 1987.

Segerstrom, Paul, Anant, T.C.A. and Dinopoulos, Elias, “A Schumpeterian Model of the Product Life Cycle". American Economic Review, Vol. 80, No. 5 , Dscember 1990; pp. 1077 - 1091.

Shell, Karl, “A Model of Inventive Activity and Capital Accumulation”, Essay IV in Karl Shell ( ed. ), Essays on the Theory of Optimal Economic Grouth M.I.T. Press, Cambridge 1967; pp. 67 - 85.

Sheshinski, Eytan, “Optimal Accumulation with Learning by Doing”, Essay I in Karl Shell (ed. ), op. cit. 1967; pp. 31 - 52.

Shleifer, Andrei " "Implementation Cycles”, Joumal of Political Economy Vo. 94, No. 6, December 1986; pp. 1163 - 1190.

Stokey, Nancy and Lucas, Robert, Recursive Methods in Economic Dynamics Harvard University Press, Cambridge 1989.

Summers, Lawrence, "Some Skeptical Observations on Real Business Cycle Theory", Quaterly Review, Federal Reserve Bank of Minneapolis, Vol. 10, No. 4, Fall 1986; pp. 23 - 27.

Summers, Robert and Heston, Alan, "Improved International Comparisons of Real Product and its Composition : $1950-1980^{\prime \prime}$, Review of Income and Wealth Series 30, No. 2, June 1984; pp. 207 - 262. 
Tirole, Jean, "Research and Development and the Adoption of New Technologies", chap. 10 in The Theory of Industrial Oranization, MIT Press, Cambridge 1988; pp. 389 - 421.

Uzawa, Hirofumi, "Optimum Technical Change in an Aggregative Model of Economic Growth", International Economic Review, Vol. 6, No. 1, January 1965; np. 18 $-31$.

Weil, Philippe . "Increasing Returns and Animal Spirits", American Economic Revieu, Vol. 79, No. 4, September 1989; pp. 889 - 894.

Weitzman, Martin, "Increasing Returns and the Foundations of Unemployment Theory", Economic Joumal Vol. 92, No. 368, December1982; pp. 787 - 804.

Zarnowitz, Victor, "Recent Work on Business Cycles in Historical Perspective", Joumal of iconomic Literature Vol. XXIII, No. 2, June 1985, pp. 523 580. 